\title{
La variabilidad tecnológica del Paleolítico superior final en el sur de Cataluña: la cueva de la Mallada (Perelló, Tarragona) y el abrigo de l'Areny (Vilanova d'Escornalbou, Tarragona)
}

Technological variability in the final Upper Palaeolithic in southern Catalonia: the cave of La Mallada Cave (Perelló, Tarragona) and the rockshelter of Areny (Vilanova d'Escornalbou, Tarragona)

\author{
Sergio García Catalán (*) \\ Manuel Vaquero Rodríguez $(*)(* *)$
}

\section{RESUMEN}

En este artículo se presenta el primer estudio tecnológico de los conjuntos líticos de la cueva de la Mallada (Perelló, Tarragona) y el abrigo de l'Areny (Vilanova d'Escornalbou, Tarragona), ambos incluidos en el Paleolítico superior final. Tras definir sus similitudes y diferencias, se han comparado con otros yacimientos con dataciones localizados principalmente en el sur de Cataluña e incluidos en este periodo cronológico. Los resultados ponen de manifiesto la variabilidad de las estrategias de explotación de núcleos al final del Paleolítico Superior.

\begin{abstract}
We present the first technological study of the lithic assemblages from the cave of La Mallada (Perelló, Tarragona) and the rockshelter of Areny (Vilanova d'Escornalbou, Tarragona), both belonging to the final Upper Palaeolithic. After defining their differences and similarities, we compared them to other sites of the same time period in southern Catalonia. Our results document the variabil-
\end{abstract}

(*) Institut Català de Paleoecologia Humana i Evolució Social (IPHES). C/ Escorxador s/n. 43003 Tarragona. España. Correo e.: sgarc64@xtec.cat

$(* *)$ Àrea de Prehistòria, Universitat Rovira i Virgili (URV). Avinguda de Catalunya 35. 43002 Tarragona. España.

Correo e.: manuel.vaquero@urv.cat

Recibido: 4-VII-2013; aceptado: 24-II-2014. ity of core reduction strategies during the final Upper Palaeolithic.

Palabras clave: Nordeste de la Península Ibérica; Pleistoceno superior final; Paleolítico superior final; Tecnología lítica; La Mallada; L'Areny.

Key words: Northeast of the Iberian Peninsula; Final upper Pleistocene; Final upper Palaeolithic; Lithic technology; La Mallada; L'Areny.

\section{INTRODUCCIÓN}

La secuencia cronocultural del Paleolítico superior final (PSF) en la vertiente mediterránea de la Península Ibérica se ha venido ordenando a partir de la distinción entre un Magdaleniense superior (MS) y un Epipaleolítico microlaminar (EM) definidos por Fortea (1973) como dos tecnocomplejos diferenciados. El MS estaría caracterizado por la talla laminar, una industria ósea típica en la que destacan los arpones, una relación buril/raspador equilibrada o favorable a los buriles y una buena presencia del utillaje microlaminar. El EM era resultado de una evolución industrial a partir del Magdaleniense, del que se diferenciaba por el aumento de los raspadores, el descenso de los buriles y la menor complejidad de la industria en hueso. 
No obstante, la continuidad de la industria lítica de estos dos tecnocomplejos dificulta establecer una línea de separación bien definida entre ellos. Esto ha provocado que se dude de la conveniencia de seguir considerando el EM como un periodo distinto al MS. En este contexto, Aura (1995) redefinió el MS y estableció tres fases. Las dos primeras, MS A y B, mantienen las características anteriormente descritas. La fase $\mathrm{C}$ correspondería al EM y se define por el predomino de los raspadores sobre los buriles, la microlitización de la industria, la reducción de la variabilidad de los elementos microlaminares y la simplificación de la industria ósea. En la misma línea, algunos autores proponen incluir la secuencia $\mathrm{MS} / \mathrm{EM}$ en el PSF (Vaquero 2004; Vaquero et al. 2009), mientras otros cuestionan la necesidad de mantener el concepto de EM y proponen el de Epimagdaleniense (Aura y Pérez 1992; Villaverde y Martínez 1995; Olaria 1999; Casabó 2004; Román 2010).

Esta problemática se debe a la gran variabilidad tecnológica y tipológica del PSF. Para explicar esta variabilidad se ha hecho hincapié en la fragmentación regional: los diferentes grupos humanos habría adaptado la industria a las necesidades económicas de los pequeños territorios ocupados. La variabilidad resultaría de los diferentes modelos de adaptación al medio (Aura y Pérez 1995; Villaverde y Martínez 1995; Casanova et al. 2008). En estas dinámicas adaptativas, las estrategias de producción de artefactos líticos constituyen un aspecto fundamental de la organización tecnológica y, como consecuencia, en la variabilidad de los conjuntos. Según algunos autores las estrategias de reducción de núcleos distinguen también el MS y el EM, sugiriendo que en el EM los procesos de talla, y en concreto la laminar, no son tan complejos y elaborados como en el MS (Domènech 1998; Soler et al. 2009). Sin embargo, los estudios tecnológicos de conjuntos del PSF mediterráneo son todavía relativamente escasos y no permiten evaluar la incidencia de los fenómenos de variabilidad regional en las dinámicas de cambio tecnológico características de este período.

En este trabajo se presenta por vez primera un estudio tecnológico del material lítico de la cueva de la Mallada (Perelló, Tarragona) y del abrigo de l'Areny (Vilanova d'Escornalbou, Tarragona), cuyas coordenadas aproximadas son 40.893979, 0.637012 y $41.099889,0.934116$ respectivamente. La documentación disponible impedía por com- pleto localizarlos con exactitud en el paraje con pequeñas cuevas y abrigos a lo largo de decenas de metros donde se encuentran. Los dos fueron excavados en los 1950 por Salvador Vilaseca e incluidos en el PSF. Desde entonces las revisiones del material siempre han sido tipológicas ya que los retocados son los elementos que, atendiendo a las propuestas de Fortea, permiten situar un conjunto dentro del MS o EM. Siguiendo estos criterios tipológicos, se ha considerado el yacimiento de la Mallada más antiguo ya que se sitúa dentro del MS, mientras que l'Areny se incluye en el EM. Nuestro estudio del material lítico, depositado en el Museo de Arqueología Salvador Vilaseca de Reus, no se basará en los retocados sino que se analizará todo el material, centrándonos en los núcleos ya que son los elementos que permiten definir los procesos de talla. Tras el análisis se compararán ambos conjuntos para definir sus similitudes y diferencias e intentar dilucidar si se simplifican las estrategias de talla como algunos autores han defendido y mantenido para el PSF, o por el contrario se mantiene la misma tradición. Por último, se buscarán paralelismos con otros yacimientos del PSF localizados sobre todo en el sur de Cataluña con dataciones radiométricas y se discutirá la conveniencia de seguir manteniendo la distinción entre MS y EM.

\section{PRESENTACIÓN DE LOS YACIMIENTOS}

\subsection{La cueva de la Mallada}

La cueva de la Mallada se localiza en el término municipal del Perelló (Baix Ebre, Tarragona) (Fig. 1). Está situada a $6 \mathrm{~km}$ al NO-O del núcleo urbano, a los pies de la sierra del Boix y a 200 $\mathrm{m}$ del abrigo con pinturas de arte levantino de Cabra-Feixet. A los pies de los dos yacimientos discurre el barranco de les Nines, que a su vez recibe otros como el de la Mallada. La cavidad tiene $20 \mathrm{~m}$ de longitud, 8 de profundidad y de altura y está orientada al Norte.

La Mallada fue descubierta en el verano de 1953 por excursionistas que recogieron 627 restos de sílex que depositaron en el Museo de Tortosa. Vilaseca se interesó por este yacimiento y un año después lo excavó. El área excavada $\left(12 \mathrm{~m}^{2}\right)$ se 


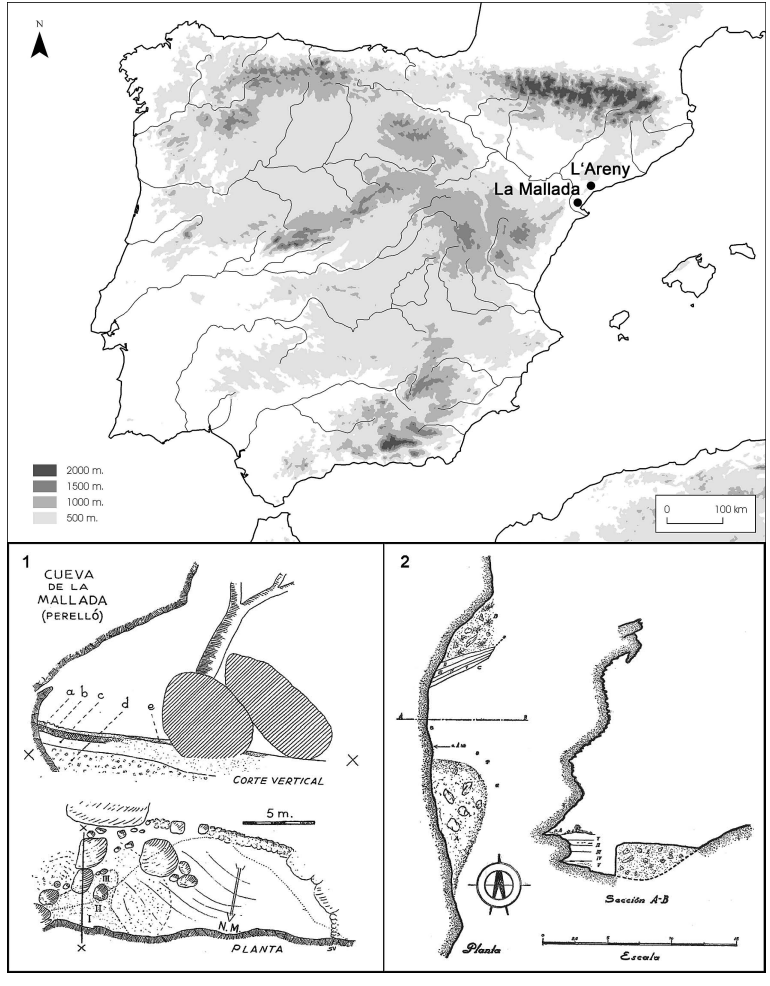

Fig. 1. Localización de la cueva de la Mallada y del abrigo de l'Areny en la Península Ibérica. 1. Planta y perfil de la cueva de la Mallada extraído de Vilaseca y Cantarell (1956); 2. Planta y alzado del abrigo de l'Areny extraído de Vilaseca (1961).

encontraba en el extremo oriental de la cueva. Se definieron 4 niveles: a, b, c, d. El c es el nivel arqueológico aunque el $\mathrm{b}$ también proporcionó algo de material (Fig. 1). Se recuperaron 1107 restos sobre sílex. Como no se observó ninguna diferenciación en el nivel arqueológico, toda la industria lítica junto a la recuperada por los excursionistas, fue considerada como un único conjunto homogéneo. Vilaseca y Cantarell (1956) lo publicaron prestando especial atención a los retocados, entre los cuales abundan los raspadores y destacan los buriles y los dorsos. En un primer momento incluyeron el material arqueológico en una edad anterior al MS en el Paleolítico superior, y más tarde Vilaseca (1961) lo atribuyó a un Epiauriñacoperigordiense algo avanzado. Fortea (1973) en su primera revisión del material no le asignó cronología, aunque después lo situó en el MS (Fortea et al. 1983). Otras publicaciones situaron la Mallada en el Magdaleniense medio (García-Argüelles y
Fullola 1987; Fullola et al. 1993), pero en la última revisión se incluyó en los momentos iniciales del MS (García-Argüelles y Nadal 1996).

Vilaseca y Cantarell (1956) mencionaron que había una abundante cantidad de restos óseos y dentarios faunísticos, que correspondían en gran parte a los géneros Capra y Cervus. En la última revisión, García-Argüelles y Nadal (1996) determinaron taxonómicamente 20 de los 181 restos disponibles sin poder identificar elementos del género Capra: 15 pertenecían a Cervus elaphus y 5 a Oryctolagus cuniculus.

\subsection{El abrigo de l'Areny}

El abrigo de l'Areny se encuentra en Vilanova d'Escornalbou (Baix Camp, Tarragona), a $2 \mathrm{~km}$ al suroeste de esta localidad y a 175 m.s.n.m. (Fig. 1). Está rodeado por el Norte, Sur y Oeste por unos acantilados de $20 \mathrm{~m}$ de altura formados por conglomerados y areniscas rojas del Trías inferior (Vilaseca 1961). En ellos se formaron dos grandes abrigos por erosión de las areniscas. El que nos ocupa se sitúa en la parte más meridional. Está orientado al Este y tiene $25 \mathrm{~m}$ de anchura, 10 de alto y 7 de profundidad.

Vilaseca (1961) descubrió l'Areny el 4 de marzo de 1956. El depósito estaba parcialmente destruido por la extracción de arenas para la fabricación de vidrio. Vilaseca inició una intervención arqueológica que acabó en 1958 en la zona intacta, es decir, en $4 \mathrm{~m}^{2}$ de la parte noroeste del yacimiento, en el fondo central del abrigo (denominado sector 5) y en el saliente de un roquedo que quedaba por encima del nivel I (sector 6), también en el fondo central. A raíz de estos trabajos, Vilaseca definió una estratigrafía con una potencia de $2,5 \mathrm{~m}$ y 5 niveles que descansaban sobre la roca natural. El nivel I era el superficial y resultó estéril, mientras que los otros cuatro (II, III, IV y V) contenían restos arqueológicos (Fig. 1). También se cribaron los depósitos situados al sudeste del abrigo y formados durante la extracción de arenas. En ellos, divididos en los sectores Pedrol y Soler, se recuperó industria lítica y cerámica.

La sedimentación fue rápida y uniforme salvo en zonas con finas capas calcáreas discontinuas que sirvieron de referencia para delimitar los niveles. A partir de la disposición de las capas, Vi- 
laseca (1961) agrupó los niveles II, III y IV, diferenciándolos del V. Esta sedimentación presentaba una horizontalidad que aprovechó Vilaseca para relacionar el sector 5 con los niveles IV y V. En el sector 6 estableció el nivel A cuya industria era muy parecida al nivel inferior.

Se recuperaron 2487 piezas de sílex, siendo los niveles III y V los más ricos. En todos los niveles dominan los raspadores, los elementos de dorso son importantes y los buriles son escasos. Vilaseca (1961) pensó que l'Areny no tenía filiación cultural con el Magdaleniense y que podría incluirse dentro del Epipaleolítico mediterráneo leptolítico, aunque al final afirmó que podía pertenecer a un Perigordiense evolucionado o bien a un Epiauriñaco-perigordiense avanzado. En la misma publicación, Laplace aseveró que debía incluirse en el Epiperigordiense final. Fortea (1973) volvió a revisar el material, agrupó los niveles III y IV y obvió el recuperado en los sectores Pedrol y Soler. Obtuvo resultados similares e incluyó l'Areny en el EM. Revisiones posteriores también lo sitúan en este periodo (Fullola y García-Argüelles 1987).

Vilaseca atestiguó la presencia de Cervus, Capra y Oryctolagus. Posteriormente, Nadal (1) identificó 24 restos de los 83 disponibles que pertenecían a Cervus elaphus, Ovis aries, Sus sp, Oryctolagus cuniculus, Meles meles y otros pequeños bóvidos y roedores. Descartó los restos de oveja por ser una especie doméstica.

\section{METODOLOGÍA DE ANÁLISIS}

El estudio del material lítico de la Mallada y l'Areny se ha centrado en aspectos morfotécnicos y tipométricos planteados en diversas propuestas metodológicas, además de determinar las materias primas utilizadas y la categoría a la que pertenece cada objeto dentro de la cadena operativa.

(1) Nadal, J. 1998: Les faunes del Plistocè final-Holocè a la Catalunya Meridional $i$ de Ponent. Interpretacions tafonòmiques $i$ paleoculturals. Tesis doctoral inédita. Universidad de Barcelona. Barcelona.

(2) Vaquero, M. 1997: Tecnología lítica y comportamiento humano: organización de las actividades técnicas y cambio diacrónico en el Paleolítico Medio del Abric Romaní (Capellades, Barcelona). Tesis doctoral inédita. Universidad Rovira i Virgili de Tarragona. Tarragona.
En el análisis morfotécnico de los núcleos se han utilizado las propuestas de Vaquero (2) y Guilbaud (1995) que permiten definir su organización volumétrica como el número de planos de intervención y su disposición con respecto a los planos del objeto (horizontal, transversal y sagital). Sobre esa base se definen los procesos de talla y las posibles relaciones de continuidad entre estos procesos. La idea principal es que las diversas estrategias pueden compartir características técnicas y que la continuidad de la explotación puede originar una nueva organización del volumen que sugiera otro tipo de estrategia.

Para las lascas se han seguido las propuestas del Sistema Lógico Analítico (Carbonell et al. 1992). Se ha analizado el tipo y preparación del talón y si este conservaba córtex, el tipo de bulbo y la corticalidad de la cara dorsal. De los retocados se ha tenido en cuenta el modo de retoque, clasificando los grupos tipológicos y tipos primarios según Laplace (1974). También se han considerado las alteraciones térmicas y si estas se produjeron antes de su configuración, como se hizo en yacimientos del PSF como el Molí del Salt (Vimbodí i Poblet, Tarragona) (Vaquero et al. 2012). Si la configuración se produce tras la exposición al fuego se puede observar macroscópicamente un brillo grasiento en el sílex. Sin embargo, el problema es diferenciar cuando la exposición es posterior al abandono de las piezas o parte de la estrategia para mejorar las cualidades del sílex y facilitar el retoque. Determinar esta intencionalidad no es sencillo y la quema accidental no se puede descartar. Eso sí, el tratamiento térmico parece superfluo para fabricar útiles del Paleolítico superior ya que, en general, no requieren complejidad técnica y, por tanto, la distribución tipológica de los retocados tras la alteración puede informar sobre el uso intencional del tratamiento térmico. Siguiendo las pautas planteadas en el Molí del Salt, para estimar el grado de importancia del reciclaje se ha calculado el índice mínimo de reciclaje (MRI) que corresponde al porcentaje de útiles quemados que fueron retocados después de la alteración.

El análisis tipométrico se ha realizado sobre lascas y retocados sobre lasca (soportes enteros) siguiendo los planteamientos de Laplace (1974). Primero se ha calculado el área (longitud por anchura) para clasificar los objetos en módulos volumétricos delimitados por intervalos de $500 \mathrm{~mm}^{2}$ que van del "Muy pequeño" al "Muy 
grande". También se ha calculado el área de los núcleos. A continuación, se ha calculado el índice de alargamiento ya que permite ver el nivel de presencia de productos laminares. Este índice relaciona longitud y anchura, y a partir de aquí clasifica los objetos en módulos de alargamiento utilizando intervalos de 0,5 . Se consideran productos laminares los incluidos a partir del módulo L5 ya que la longitud dobla la anchura. También se ha calculado el índice de carenado a partir de la relación entre la menor de las dos dimensiones planas (longitud o anchura) y el grosor. A partir de aquí los productos se distribuyen en módulos con intervalos de 1, considerando elementos carenados o espesos los incluidos dentro de los módulos $\mathrm{C} 1-\mathrm{C} 4$ y estrechos a partir del C5.

\section{RESULTADOS}

\subsection{La industria lítica de la Mallada}

Se han analizado 1662 restos líticos, incluidos los recuperados por los excursionistas ya que ni su estado de conservación, ni ningún otro indicio desestiman su inclusión en este estudio. La materia prima dominante es el sílex $(91,5 \%)$, seguido del ágata $(8,5 \%)$. Un elemento sobre cristal de roca es testimonial (Tab. 1). Las categorías más representadas son los fragmentos de lasca y las lascas (dos tercios del total). Los retocados son el 7,8\% y los núcleos el 1,3\%.

Se ha de destacar el estado de conservación del material. En el 56,3\% una pátina blanca de alteración afecta a la parte externa e interna. La superficie en muchos casos aparece desintegrada y alterada provocando la pérdida de materia. García-Argüelles y Nadal (1996) hablan de deshidratación, pero esta alteración también podría ser producto de la desilificación provocada por el agua, por la composición del terreno o por las propiedades de la materia prima ya que las impurezas favorecen esta alteración (Font et al. 2010). La causa de la alteración no queda clara pero es evidente que afecta mucho más al sílex $(60,3 \%)$ que al ágata. Además una cuarta parte del sílex muestra un alto grado de alteración y pérdida de materia. En cambio, sólo el 12,8\% de elementos sobre ágata han sido alterados y solo uno ha perdido materia. Las alteraciones térmicas afectan al $45 \%$ del material y son más relevantes en el ágata (61\%) que en el sílex (43,6\%).

Se han recuperado 22 núcleos de dimensiones reducidas: 14 se incluyen en el módulo "Pequeño", 2 en el "Muy pequeño", 3 en el "Grande", 2 en el "Muy Grande" y 1 en el "Mediano". Esta distribución y el momento de la secuencia de talla en que se ubica cada uno nos aproximan al grado de reducción. Hay 11 núcleos en la fase de explotación plena, 9 en la final y 2, los más grandes y sin una organización volumétrica definida, en la inicial. Los datos indican que el grado de explotación es muy alto.

Estos 22 núcleos presentan 31 planos de intervención con 15 núcleos unipolares, 5 bipolares y 2 con tres planos. El plano transversal es el más utilizado con 19 seguido del horizontal con 8 y del sagital con 4. Este uso diferencial del plano transversal es coherente ya que en el PSF la talla laminar juega un papel relevante, y la explotación de este plano permite obtener productos alargados donde se maximiza la longitud sobre la anchura.

\begin{tabular}{|c|c|c|c|c|c|c|c|c|}
\hline & Lascas & Núcleos & $\begin{array}{l}\text { Artefactos } \\
\text { retocados }\end{array}$ & $\begin{array}{c}\text { Lascas } \\
\text { fracturadas }\end{array}$ & $\begin{array}{c}\text { Fragmentos } \\
\text { de lasca }\end{array}$ & Fragmentos & $\begin{array}{c}\text { Restos } \\
\text { de talla }\end{array}$ & Total \\
\hline Sílex & $\begin{array}{c}455 \\
27,4 \%\end{array}$ & $\begin{array}{c}20 \\
1,2 \%\end{array}$ & $\begin{array}{c}124 \\
7,5 \%\end{array}$ & $\begin{array}{c}216 \\
13 \%\end{array}$ & $\begin{array}{c}495 \\
29,8 \%\end{array}$ & $\begin{array}{c}94 \\
5,7 \%\end{array}$ & $\begin{array}{l}116 \\
7 \%\end{array}$ & $\begin{array}{c}1520 \\
91,5 \%\end{array}$ \\
\hline Ágata & $\begin{array}{c}51 \\
3,1 \% \\
\end{array}$ & $\begin{array}{c}2 \\
, 1 \%\end{array}$ & $\begin{array}{c}5 \\
, 3 \% \\
\end{array}$ & $\begin{array}{c}25 \\
1,5 \%\end{array}$ & $\begin{array}{c}42 \\
2,5 \%\end{array}$ & $\begin{array}{c}11 \\
, 7 \% \\
\end{array}$ & $\begin{array}{c}5 \\
, 3 \% \\
\end{array}$ & $\begin{array}{c}141 \\
8,5 \%\end{array}$ \\
\hline $\begin{array}{c}\text { Cristal de } \\
\text { cuarzo }\end{array}$ & $\begin{array}{c}1 \\
0 \%\end{array}$ & & & & & & & $\begin{array}{c}1 \\
0 \%\end{array}$ \\
\hline Total & $\begin{array}{c}507 \\
\mathbf{3 0 , 5} \%\end{array}$ & $\begin{array}{c}22 \\
1,3 \%\end{array}$ & $\begin{array}{c}129 \\
7,8 \%\end{array}$ & $\begin{array}{c}241 \\
14,5 \%\end{array}$ & $\begin{array}{c}537 \\
32,3 \% \\
\end{array}$ & $\begin{array}{c}105 \\
6,3 \%\end{array}$ & $\begin{array}{c}121 \\
7,3 \%\end{array}$ & $\begin{array}{c}1662 \\
100 \%\end{array}$ \\
\hline
\end{tabular}

Tab. 1. Distribución de los restos líticos de cueva de la Mallada por categorías y materias primas.

Trab. Prehist., 72, N. ${ }^{\circ}$ 1, enero-junio 2015, pp. 64-83, ISSN: 0082-5638

doi: $10.3989 /$ tp.2015.12144 
La explotación en superficie y en volumen no son formas de explotación independientes ya que en un mismo proceso técnico se podría utilizar una y otra sucesivamente. La aplicación de una $\mathrm{u}$ otra ayuda a explicar la variabilidad en la organización volumétrica de los núcleos. Dicha organización y la disposición de las extracciones ha permitido diferenciar 5 modelos con una variabilidad interna definida por el número y la disposición de los planos de intervención y el tipo de extracciones. Estos modelos tampoco han de ser vistos como independientes ya que pueden compartir características y en algunos casos se puede ver una línea de continuidad entre núcleos con una organización del volumen diferente.

El modelo de organización volumétrica más destacado presenta una explotación longitudinal con jerarquización facial ( $\mathrm{n}=11)$ (Fig. 2). En este caso se estructura el volumen del núcleo con dos caras opuestas separadas por un plano de intersección y ortogonales a los planos de intervención. Una de las caras presenta los negativos de los productos obtenidos, pero no la opuesta y en algunos casos conserva parte cortical. Son 11 núcleos sobre sílex, salvo los números 3 y 8 sobre ágata: 8 son unipolares, 6 explotados desde el transversal, 2 desde el sagital y 3 son bipolares. Un bipolar es explotado desde el horizontal y sagital, otro desde el horizontal y transversal (Fig. 2: 1) y en el tercero sobre ágata se utilizan los dos transversales (Fig. 2: 8). La mayor utilización del plano transversal favorece que las extracciones sean laminares o de tendencia laminar. Además, en todos los casos se observa una única serie de extracciones unidireccionales y paralelas. Estos 11 núcleos reflejan una talla en superficie aunque en los números 4 y 8 ya se intuye una talla en volumen aprovechando la arista que separa ambas caras. En los núcleos 3 y 5 si se hubiese continuado la reducción desde el mismo plano de intervención se hubiese pasado a la talla en volumen. En los números 1, 2 y 6 se produce la explotación de lascas espesas. El 6 presenta una talla laminar iniciada desde el flanco derecho aprovechando la propia arista de la lasca (generada por la unión de la cara ventral y dorsal) como guía para facilitar la primera extracción, y a partir de aquí continuar las extracciones laminares de derecha a izquierda que quedan reflejadas en la cara ventral.

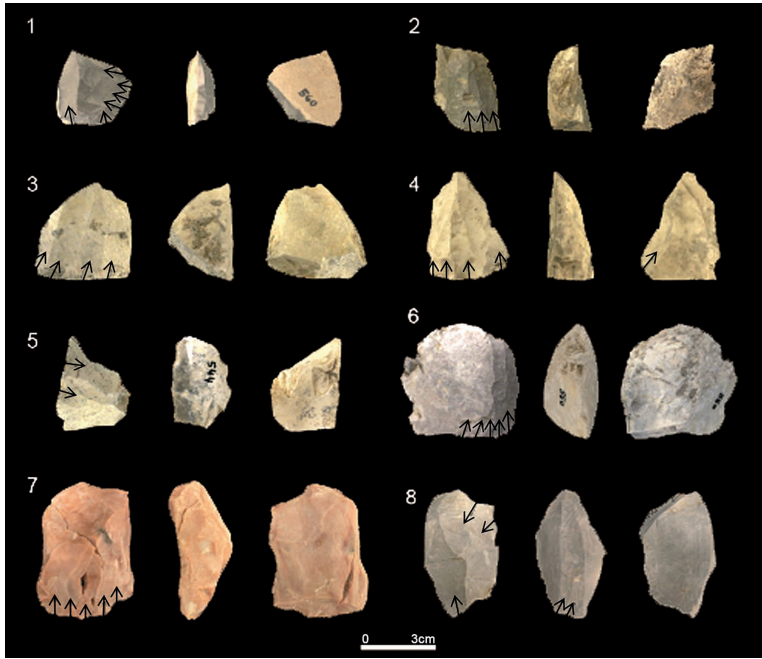

Fig. 2. Núcleos recuperados en la Mallada con explotación longitudinal y jerarquización facial (fotografías Sergio García).

El segundo modelo incluye los núcleos con explotación longitudinal y talla en volumen $(n=4)$ : 3 desde el plano transversal y 1 desde el sagital (Fig. 3: 1-4). Todos ellos presentan una explotación casi total del perímetro que define los planos de intervención y evidencian una talla laminar que ha provocado que tengan una morfología piramidal. En el número 1 se observan pequeños levantamientos para configurar una arista guía y generar una lámina de cresta que permita iniciar esta talla laminar. El número 2 carece de extracciones a lo largo de su volumen ya que hay una parte tallada en contraposición con otra no tallada y, por tanto, refleja una continuidad con los núcleos con jerarquización facial.

El tercer tipo es de estructura discoidal con extracciones centrípetas $(n=1)$ (Fig. 3: 5). La talla es en superficie, su estructura viene definida por dos planos opuestos separados por otro de intersección y las extracciones se realizan desde el plano horizontal. Es un núcleo bifacial ya que tiene extracciones centrípetas en ambas caras. Se pretende obtener lascas sin necesidad que sean laminares.

Los modelos restantes son los núcleos poliédricos y los expeditivos, explotados de forma oportunista y sin una organización volumétrica definida o simplemente sin intención por parte del tallador de preparar el volumen. Se han determinado 2 núcleos poliédricos con tres pla- 


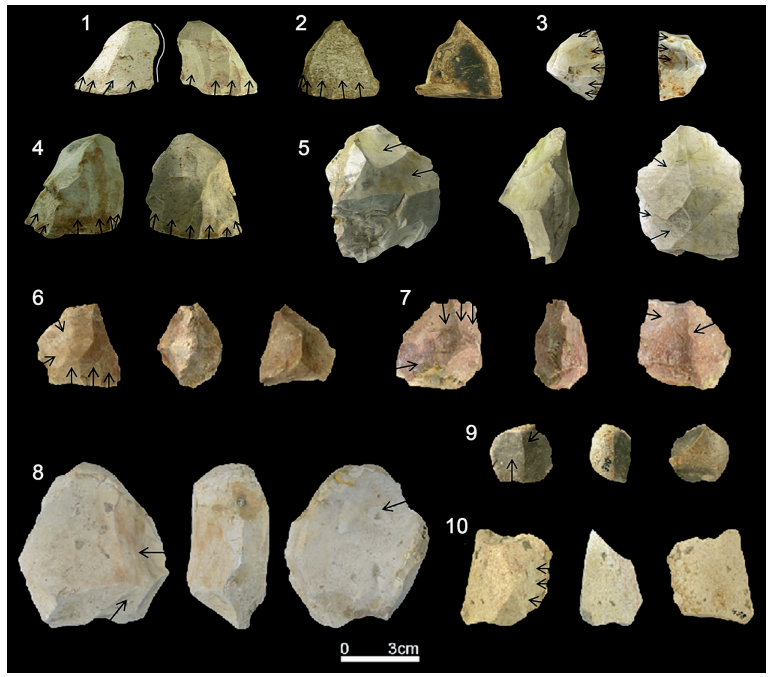

Fig. 3. La Mallada: 1-4. núcleos con explotación longitudinal y en volumen; 5 . núcleo centrípeto con estructura discoidal; 6-7. núcleos poliédricos; 8-10. núcleos expeditivos (fotografías Sergio García).

nos de intervención y extracciones en diversas caras (Fig. 3: 6-7). Uno es explotado desde los dos transversales y un horizontal (Fig. 3: 6) y el otro desde los dos horizontales y un transversal (Fig. 3: 7). En ambos casos la mayor parte de las extracciones se realizan desde el plano transversal y presentan una tendencia laminar, mientras que desde el horizontal son levantamientos cortos. Hay 4 núcleos expeditivos (Fig. 3: 8-10): 2 unipolares (uno desde el transversal y otro desde el horizontal) y 2 bipolares (uno desde los dos transversales y el otro desde el transversal y horizontal). La talla en estos núcleos no está orientada a obtener productos laminares o con tendencia laminar si no productos rápidos $\mathrm{y}$ sin esfuerzo. Estos levantamientos son más bien cortos salvo el número 8 , el cual se encuentra en una fase inicial y muestra extracciones de grandes dimensiones.

Lo expuesto pone en evidencia el papel destacado de la talla laminar en las estrategias de talla, como reafirma la presencia de tres láminas de cresta y diversas lascas con sección triangular muy abrupta que se generan aprovechando la arista natural formada por la unión de dos planos y que permiten el inicio de la talla laminar.

El análisis de las lascas ha excluido la de cristal de roca. Contamos con 506: 455 sobre sílex y 51 sobre ágata. Respecto a sus características tipométricas, la media de las tres dimensiones es ligeramente superior en las lascas de ágata, lo cual se corrobora con la distribución por módulos volumétricos (Tab. 2). El 90,7\% de las lascas se incluyen en los dos módulos más pequeños con el $60,5 \%$ en el "Muy pequeño" donde hay más lascas sobre sílex que sobre ágata. En los módulos "Grande" y "Muy grande" sólo se ubican lascas sobre sílex, aunque su presencia es poco significativa. Los productos laminares representan el 18\% del índice de alargamiento (Tab. 3), con el $21,5 \%$ sobre ágata frente al $17,6 \%$ sobre sílex. Sin embargo, si se tuviesen en cuenta las lascas fracturadas y los fragmentos de lasca, así como los retocados, este índice laminar aumentaría. Además, la mitad de las lascas presentan características propias de las láminas como los filos paralelos y la sección triangular o trapezoidal. El índice de carenado permite concluir que las lascas son más bien espesas o carenadas ya que sólo el $17,1 \%$ se pueden considerar estrechas (Tab. 4). Las lascas estrechas sobre sílex son ligeramente superiores a las lascas sobre ágata.

El análisis morfotécnico de las lascas muestra que, en general, el talón es no cortical, unifacetado y el tipo que predomina es la plataforma $(58,3 \%)$ sobre el talón lineal $(30,4 \%)$ y el puntiforme $(11,3 \%)$. En la cara ventral destaca el bulbo difuso (63\%) sobre el marcado (37\%). Domina la cara dorsal no cortical $(69,6 \%)$. Las lascas con la mayor parte cortical o enteramente corticales sólo llegan al 9,3\%. Las diferencias significativas entre

\begin{tabular}{|c|c|c|c|c|c|c|}
\hline & $\begin{array}{c}\text { Muy } \\
\text { pequeño }\end{array}$ & Pequeño & Mediano & Grande & $\begin{array}{c}\text { Muy } \\
\text { grande }\end{array}$ & Total \\
\hline $\begin{array}{c}\text { Lascas } \\
\text { sobre } \\
\text { sílex }\end{array}$ & $\begin{array}{c}283 \\
62,2 \%\end{array}$ & $\begin{array}{c}129 \\
28,4 \%\end{array}$ & $\begin{array}{c}27 \\
5,9 \%\end{array}$ & $\begin{array}{c}10 \\
2,2 \%\end{array}$ & $\begin{array}{c}6 \\
1,3 \%\end{array}$ & $\begin{array}{c}\mathbf{4 5 5} \\
\mathbf{1 0 0} \%\end{array}$ \\
\hline $\begin{array}{c}\text { Lascas } \\
\text { sobre } \\
\text { ágata }\end{array}$ & $\begin{array}{c}23 \\
45,1 \%\end{array}$ & $\begin{array}{c}24 \\
47,1 \%\end{array}$ & $\begin{array}{c}4 \\
7,8 \%\end{array}$ & & & $\mathbf{5 1}$ \\
\hline $\begin{array}{c}\text { Total de } \\
\text { lascas }\end{array}$ & $\mathbf{3 0 6}$ & $\mathbf{1 5 3}$ & $\mathbf{3 1}$ & $\mathbf{1 0}$ & $\mathbf{6}$ & $\mathbf{6}$ \\
\hline $\begin{array}{c}\text { Retocados } \\
\text { sobre }\end{array}$ & $\begin{array}{c}\mathbf{3 0 , 2} \% \\
\text { lasca }\end{array}$ & $\mathbf{6 , 1} \%$ & $\mathbf{2} \%$ & $\mathbf{1 , 2} \%$ & $\mathbf{5 0 6} \%$ \\
\hline
\end{tabular}

Tab. 2. Distribución de las lascas y los retocados sobre lasca de la Mallada por módulos volumétricos y materias primas. 


\begin{tabular}{|c|c|c|c|c|c|c|c|c|c|}
\hline & $\mathbf{L 1}$ & L2 & $\mathbf{L 3}$ & L4 & L5 & L6 & L7 & L8 & Total \\
\hline $\begin{array}{c}\text { Lascas } \\
\text { sobre sílex }\end{array}$ & $\begin{array}{c}4 \\
, 9 \% \\
\end{array}$ & $\begin{array}{c}112 \\
24,6 \% \\
\end{array}$ & $\begin{array}{c}156 \\
34,3 \% \\
\end{array}$ & $\begin{array}{c}103 \\
22,6 \% \\
\end{array}$ & $\begin{array}{c}40 \\
8,8 \% \\
\end{array}$ & $\begin{array}{c}23 \\
5,1 \% \\
\end{array}$ & $\begin{array}{c}11 \\
2,4 \% \\
\end{array}$ & $\begin{array}{c}6 \\
1,3 \% \\
\end{array}$ & $\begin{array}{c}455 \\
100 \% \\
\end{array}$ \\
\hline $\begin{array}{c}\text { Lascas } \\
\text { sobre ágata }\end{array}$ & $\begin{array}{c}1 \\
2 \%\end{array}$ & $\begin{array}{c}10 \\
19,6 \%\end{array}$ & $\begin{array}{c}18 \\
35,3 \%\end{array}$ & $\begin{array}{c}11 \\
21,6 \%\end{array}$ & $\begin{array}{c}4 \\
7,8 \%\end{array}$ & $\begin{array}{c}3 \\
5,9 \%\end{array}$ & $\begin{array}{c}4 \\
7,8 \%\end{array}$ & & $\begin{array}{c}51 \\
100 \%\end{array}$ \\
\hline $\begin{array}{c}\text { Total } \\
\text { de lascas }\end{array}$ & $\begin{array}{c}5 \\
1 \%\end{array}$ & $\begin{array}{c}122 \\
24,1 \%\end{array}$ & $\begin{array}{c}174 \\
34,4 \%\end{array}$ & $\begin{array}{c}114 \\
22,5 \%\end{array}$ & $\begin{array}{c}44 \\
8,7 \%\end{array}$ & $\begin{array}{c}26 \\
5,1 \%\end{array}$ & $\begin{array}{c}15 \\
3 \%\end{array}$ & $\begin{array}{c}6 \\
1,2 \%\end{array}$ & $\begin{array}{r}506 \\
100 \%\end{array}$ \\
\hline
\end{tabular}

\begin{tabular}{|c|c|c|c|c|c|c|c|}
\hline & L2 & L3 & L4 & L5 & L7 & L9 & Total \\
\hline \multirow{2}{*}{ Retocados sobre lasca } & 15 & 16 & 7 & 1 & 1 & 2 & $\mathbf{4 2}$ \\
& $35,7 \%$ & $38,1 \%$ & $16,7 \%$ & $2,4 \%$ & $2,4 \%$ & $4,8 \%$ & $\mathbf{1 0 0 \%}$ \\
\hline
\end{tabular}

Tab. 3. Distribución de las lascas y los retocados sobre lasca de la Mallada por módulos de alargamiento y materias primas.

\begin{tabular}{|c|c|c|c|c|c|c|c|c|}
\hline & $\mathrm{C1}$ & $\mathrm{C2}$ & C3 & $\mathrm{C} 4$ & C5 & C6 & C7 & Total \\
\hline $\begin{array}{c}\text { Lascas sobre } \\
\text { sílex }\end{array}$ & $\begin{array}{c}2 \\
, 4 \% \\
\end{array}$ & $\begin{array}{c}59 \\
13 \% \\
\end{array}$ & $\begin{array}{c}181 \\
39,8 \% \\
\end{array}$ & $\begin{array}{c}133 \\
29,2 \% \\
\end{array}$ & $\begin{array}{c}56 \\
12,3 \% \\
\end{array}$ & $\begin{array}{c}20 \\
4,4 \% \\
\end{array}$ & $\begin{array}{c}4 \\
, 9 \% \\
\end{array}$ & $\begin{array}{r}455 \\
100 \% \\
\end{array}$ \\
\hline $\begin{array}{c}\text { Lascas sobre } \\
\text { ágata }\end{array}$ & & $\begin{array}{c}7 \\
13,7 \% \\
\end{array}$ & $\begin{array}{c}16 \\
31,4 \% \\
\end{array}$ & $\begin{array}{c}22 \\
43,1 \% \\
\end{array}$ & $\begin{array}{c}4 \\
7,8 \% \\
\end{array}$ & $\begin{array}{c}1 \\
2 \% \\
\end{array}$ & $\begin{array}{c}1 \\
2 \% \\
\end{array}$ & $\begin{array}{c}51 \\
100 \% \\
\end{array}$ \\
\hline $\begin{array}{c}\text { Total } \\
\text { de lascas }\end{array}$ & $\begin{array}{c}2 \\
, 4 \%\end{array}$ & $\begin{array}{c}66 \\
13 \%\end{array}$ & $\begin{array}{c}197 \\
38,9 \%\end{array}$ & $\begin{array}{c}155 \\
30,6 \%\end{array}$ & $\begin{array}{c}60 \\
11,9 \%\end{array}$ & $\begin{array}{c}21 \\
4,2 \%\end{array}$ & $\begin{array}{c}5 \\
1 \%\end{array}$ & $\begin{array}{r}506 \\
100 \%\end{array}$ \\
\hline
\end{tabular}

\begin{tabular}{|c|c|c|c|c|c|c|}
\hline & C2 & C3 & C4 & C5 & C8 & Total \\
\hline \multirow{2}{*}{ Retocados sobre lasca } & 13 & 16 & 9 & 3 & 1 & $\mathbf{4 2}$ \\
& $31 \%$ & $38,1 \%$ & $21,4 \%$ & $7,1 \%$ & $2,4 \%$ & $\mathbf{1 0 0} \%$ \\
\hline
\end{tabular}

Tab. 4. Distribución de las lascas y los retocados sobre lasca de la Mallada por módulos de carenado y materias primas.

las lascas de sílex $(28,8 \%)$ y de ágata $(45,1 \%)$ permiten inferir que los nódulos de ágata serían aportados al yacimiento menos desbastados que los de sílex.

Los retocados de la Mallada suman un total de 129: 124 sobre sílex y 5 sobre ágata. De ellos 42 están configurados sobre lasca, 14 sobre lasca fracturada y 73 sobre fragmento de lasca. La tipometría se ha estudiado en los elaborados sobre lasca y la media de sus tres dimensiones evidencia valores superiores a los de las lascas no retocadas, lo que sugiere que el tamaño era un criterio importante a la hora de seleccionar los soportes para ser configurados. Esto se corrobora si se observa la distribución por módulos volumétricos (Tab. 2). Los módulos "Muy pequeño" y "Pequeño" representan un 59,5\% de los retocados en contraste con el $90,7 \%$ de las lascas, mientras que en los módulos "Grande" y "Muy grande" se encuentran el $19,1 \%$ de los retocados en contraposición con el 3,2\% de lascas. El test del $\mathrm{x}^{2}$ reafirma estadísticamente que hay una tendencia a seleccionar soportes más grandes para la configuración $\left(\mathrm{x}^{2}=50,96 ; \mathrm{gl}=4 ; \mathrm{P}<0,05\right)$. El índice de alargamiento muestra que el $9,6 \%$ de retocados se incluyen en los módulos laminares frente al $18 \%$ de las lascas (Tab. 3). Sin embargo, si tuviéramos en cuenta todos los retocados este porcentaje subiría al $28 \%$ ya que los dorsos están fracturados a excepción de dos. Según el índice de carenado sólo 4 piezas $(9,5 \%)$ se pueden considerar estrechas (Tab. 4). Si se compara con el de las lascas, este porcentaje baja diez puntos. Es decir, se buscan soportes más bien espesos a la hora de configurar pero la mayoría de dorsos no aparecen reflejados. 


\begin{tabular}{|c|c|c|c|c|c|c|c|c|c|c|c|c|}
\hline & S & $\mathbf{G}$ & $\mathbf{R}$ & $\mathbf{D}$ & $\mathbf{A}$ & $\mathbf{B c}$ & $\mathbf{T}$ & $\mathbf{L D}$ & $\mathbf{L D T}$ & $\mathbf{P D}$ & $\mathbf{B}$ & Total \\
\hline La & 12 & 37 & 7 & 14 & 4 & 5 & & 21 & 4 & 5 & 26 & $\mathbf{1 3 5}$ \\
Mallada & $8,9 \%$ & $27,4 \%$ & $5,2 \%$ & $10,4 \%$ & $2,9 \%$ & $3,7 \%$ & & $15,6 \%$ & $2,9 \%$ & $3,7 \%$ & $19,3 \%$ & $\mathbf{1 0 0} \%$ \\
\hline \multirow{2}{*}{ LAreny } & 10 & 63 & 4 & 23 & 6 & 4 & 3 & 33 & 1 & 12 & 4 & $\mathbf{1 6 3}$ \\
& $6,1 \%$ & $38,7 \%$ & $2,5 \%$ & $14,1 \%$ & $3,7 \%$ & $2,5 \%$ & $1,8 \%$ & $20,2 \%$ &, $6 \%$ & $7,4 \%$ & $2,5 \%$ & $\mathbf{1 0 0} \%$ \\
\hline
\end{tabular}

Tab. 5. Distribución de los tipos primarios de la Mallada y de l'Areny por grupos tipológicos.
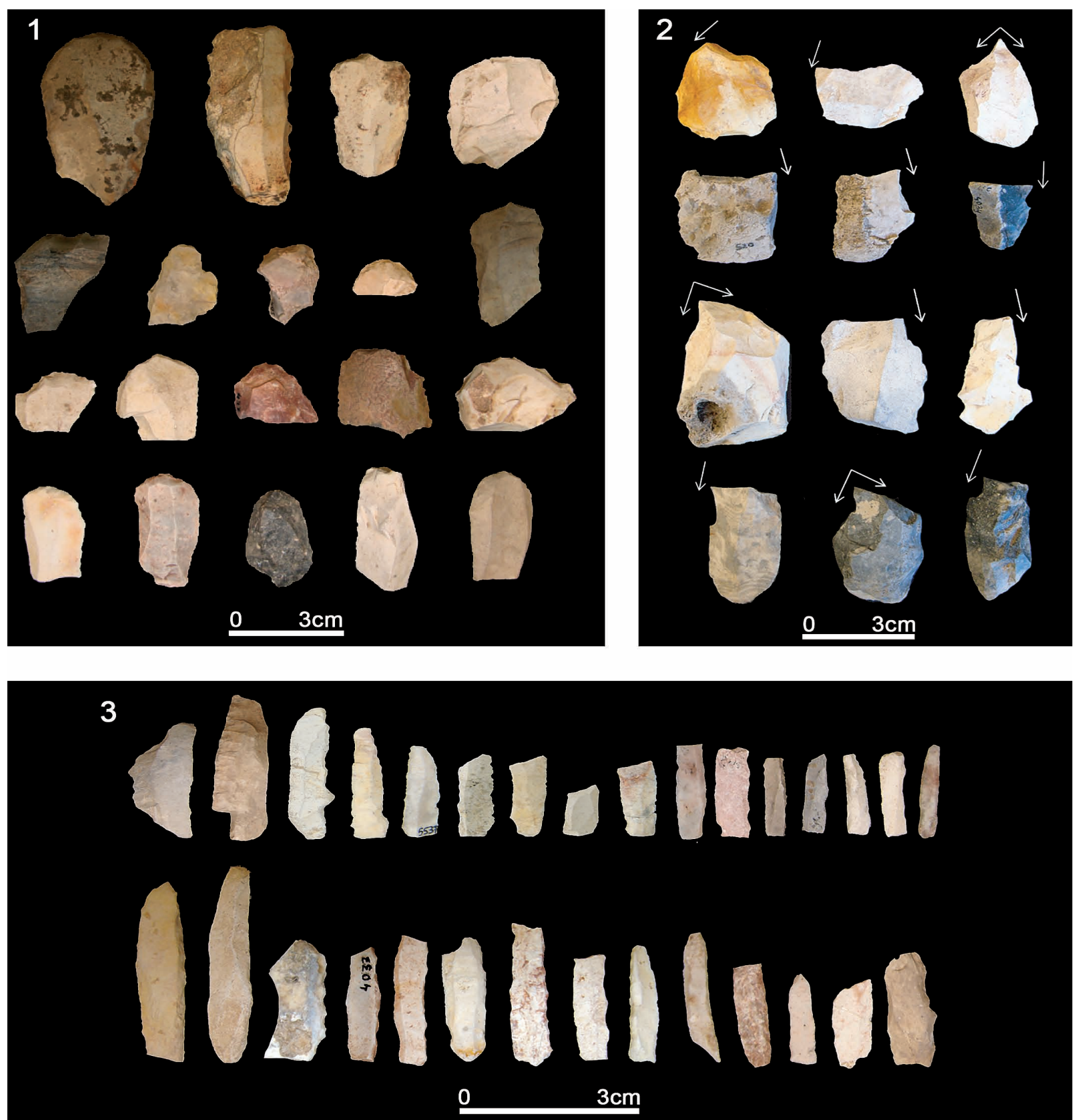

Fig. 4. Artefactos retocados recuperados en la Mallada: 1. Raspadores; 2. Buriles; 3. Elementos de dorso (fotografías Sergio García).

Trab. Prehist., 72, N. ${ }^{\circ}$ 1, enero-junio 2015, pp. 64-83, ISSN: 0082-5638 doi: $10.3989 /$ tp.2015.12144 


\begin{tabular}{|c|c|c|c|c|c|c|c|c|c|c|c|c|c|c|c|}
\hline & Sind & G11 & G12 & G21 & G22 & R11 & R21 & D21 & D22 & D23 & D25 & $\mathbf{A}$ & Bc1 & T21 & $\mathrm{T} 22$ \\
\hline $\begin{array}{c}\text { La } \\
\text { Mallada }\end{array}$ & $\begin{array}{c}12 \\
8,9 \%\end{array}$ & $\begin{array}{c}30 \\
22,2 \%\end{array}$ & $\begin{array}{c}4 \\
3 \% \\
\end{array}$ & $\begin{array}{c}3 \\
2,2 \%\end{array}$ & & & $\begin{array}{c}7 \\
5,2 \% \\
\end{array}$ & $\begin{array}{c}9 \\
6,7 \% \\
\end{array}$ & $\begin{array}{c}1 \\
, 7 \% \\
\end{array}$ & $\begin{array}{c}3 \\
2,2 \%\end{array}$ & $\begin{array}{c}1 \\
, 7 \% \\
\end{array}$ & $\begin{array}{c}4 \\
3 \% \\
\end{array}$ & $\begin{array}{c}5 \\
3,7 \% \\
\end{array}$ & & \\
\hline L'Areny & $\begin{array}{c}10 \\
6,1 \%\end{array}$ & $\begin{array}{c}57 \\
35 \% \\
\end{array}$ & $\begin{array}{c}5 \\
3,1 \% \\
\end{array}$ & & $0,6 \%$ & $\begin{array}{c}1 \\
0,6 \%\end{array}$ & $\begin{array}{c}3 \\
1,8 \%\end{array}$ & $\begin{array}{c}8 \\
4,9 \%\end{array}$ & $\begin{array}{c}5 \\
3,1 \%\end{array}$ & $\begin{array}{c}7 \\
4,3 \%\end{array}$ & $\begin{array}{c}3 \\
1,8 \%\end{array}$ & $\begin{array}{c}6 \\
3,7 \%\end{array}$ & $\begin{array}{c}4 \\
2,5 \%\end{array}$ & $\begin{array}{c}2 \\
1,2 \% \\
\end{array}$ & $\begin{array}{c}1 \\
0,6 \%\end{array}$ \\
\hline & LD21 & LD22 & LD' & & PD21 & PD22 & PD23 & PD25 & PD31 & B12 & B21 & B22 & B23 & B32 & Total \\
\hline $\begin{array}{c}\text { La } \\
\text { Mallada }\end{array}$ & $\begin{array}{c}20 \\
14,8 \% \\
\end{array}$ & $\begin{array}{c}1 \\
, 7 \% \\
\end{array}$ & 3 & & & & $\begin{array}{c}3 \\
2,2 \% \\
\end{array}$ & & $\begin{array}{c}2 \\
1,5 \%\end{array}$ & $\begin{array}{c}17 \\
12,6 \%\end{array}$ & $\begin{array}{c}1 \\
, 7 \%\end{array}$ & $\begin{array}{c}1 \\
, 7 \%\end{array}$ & $\begin{array}{c}3 \\
2,2 \%\end{array}$ & $\begin{array}{c}4 \\
3 \% \\
\end{array}$ & $\begin{array}{l}135 \\
100\end{array}$ \\
\hline L'Areny & $\begin{array}{c}31 \\
19 \%\end{array}$ & $\begin{array}{c}2 \\
1,2 \%\end{array}$ & 0,6 & & $\begin{array}{c}1 \\
0,6 \%\end{array}$ & $\begin{array}{c}2 \\
1,2 \%\end{array}$ & $\begin{array}{c}8 \\
4,9 \%\end{array}$ & $\begin{array}{c}1 \\
0,6 \%\end{array}$ & & $\begin{array}{c}3 \\
1,8 \%\end{array}$ & & $\begin{array}{c}1 \\
0,6 \%\end{array}$ & & & $\begin{array}{c}163 \\
100 \%\end{array}$ \\
\hline
\end{tabular}

Tab. 6. Distribución de todos los retocados de la Mallada y de l'Areny por tipos primarios.

De los 129 retocados 6 son compuestos, lo que supone 135 tipos primarios. El retoque dominante es el simple $(37,8 \%)$ seguido del abrupto $(32,6 \%)$ y del buril $(19,3 \%)$. El retoque semiabrupto $(10,3 \%)$, intermedio entre los dos primeros, configura raspadores y un denticulado. En los grupos tipológicos (Tab. 5 y Fig. 4) predominan los raspadores $(27,4 \%)$, los dorsos $(22,3 \%)$ y los buriles (19,3\%). En los tipos primarios predomina el raspador frontal simple (G11), la lámina de dorso profundo (LD21), el buril sobre fractura (B12) y la muesca (D21) (Tab. 6).

Hay 51 artefactos retocados quemados $(39,5 \%$ del total). Tras la alteración térmica se retocaron 5 (MRI del 9,8\%): 2 denticulados, 2 raspadores y 1 artefacto doble formado por una muesca y un raspador donde sólo la muesca se ha configurado después de la alteración. Parece que se utilizan soportes quemados para manufacturar útiles que no requieren un alto nivel técnico, lo que sugiere un reciclaje de carácter expeditivo. Se ha de tener presente que el MRI subestima la importancia real del reciclaje en la Mallada por el estado de conservación del material que dificulta ver con claridad el lustre. Si únicamente nos atenemos al MRI, el reciclaje en la Mallada es menor que en Molí del Salt (Vaquero et al. 2012), donde el MRI llega al $20,4 \%$ y el reciclaje también es expeditivo.

\subsection{La industria lítica de l'Areny}

El estudio se ha centrado exclusivamente en la industria recuperada en los niveles arqueológicos ya que el registro restante aparece junto a cerámica y fuera de contexto. Como las características del material de estos niveles son homogéneas se ha considerado un único conjunto. Se han estudiado 2003 piezas talladas casi todas de sílex y alguna de ágata (Tab. 7). Las cuarcitas, calizas y esquistos forman parte, salvo 2 lascas sobre cuarcita, de los fragmentos y las bases naturales utilizadas como percutores. Si obviamos los restos inferiores al centímetro de longitud, las categorías

\begin{tabular}{|c|c|c|c|c|c|c|}
\hline & Sílex & Ágata & Cuarcita & Caliza & Esquisto & Total \\
\hline $\begin{array}{c}\text { Bases } \\
\text { naturales }\end{array}$ & & & $\begin{array}{c}3 \\
, 2 \%\end{array}$ & & $\begin{array}{c}1 \\
0 \%\end{array}$ & $\begin{array}{c}4 \\
, 2 \%\end{array}$ \\
\hline Núcleos & $\begin{array}{c}29 \\
1,4 \%\end{array}$ & $\begin{array}{c}1 \\
0 \%\end{array}$ & & & & $\begin{array}{c}30 \\
1,5 \%\end{array}$ \\
\hline Lascas & $\begin{array}{c}468 \\
23,4 \%\end{array}$ & $\begin{array}{c}8 \\
, 4 \%\end{array}$ & $\begin{array}{c}2 \\
, 1 \%\end{array}$ & & & $\begin{array}{c}478 \\
23,9 \%\end{array}$ \\
\hline $\begin{array}{c}\text { Lascas } \\
\text { fracturadas }\end{array}$ & $\begin{array}{c}236 \\
11,8 \%\end{array}$ & $\begin{array}{c}2 \\
, 1 \%\end{array}$ & & & & $\begin{array}{c}238 \\
11,9 \%\end{array}$ \\
\hline $\begin{array}{c}\text { Fragmentos } \\
\text { de lasca }\end{array}$ & $\begin{array}{c}444 \\
22,2 \%\end{array}$ & $\begin{array}{l}11 \\
, 5 \%\end{array}$ & & & & $\begin{array}{c}455 \\
22,7 \%\end{array}$ \\
\hline $\begin{array}{l}\text { Artefactos } \\
\text { retocados }\end{array}$ & $\begin{array}{c}155 \\
7,7 \%\end{array}$ & $\begin{array}{c}4 \\
, 2 \%\end{array}$ & & & & $\begin{array}{c}159 \\
7,9 \%\end{array}$ \\
\hline Fragmentos & $\begin{array}{c}56 \\
2,8 \% \\
\end{array}$ & $\begin{array}{c}5 \\
, 2 \%\end{array}$ & $\begin{array}{c}1 \\
0 \%\end{array}$ & $\begin{array}{c}2 \\
, 1 \%\end{array}$ & & $\begin{array}{c}64 \\
3,2 \% \\
\end{array}$ \\
\hline $\begin{array}{l}\text { Restos de } \\
\text { talla }\end{array}$ & $\begin{array}{c}562 \\
28,1 \%\end{array}$ & $\begin{array}{c}13 \\
0,6 \%\end{array}$ & & & & $\begin{array}{c}575 \\
28,7 \%\end{array}$ \\
\hline Total & $\begin{array}{r}1950 \\
97,4 \%\end{array}$ & $\begin{array}{c}44 \\
2,2 \%\end{array}$ & $\begin{array}{c}6 \\
, 3 \%\end{array}$ & $\begin{array}{c}2 \\
, 1 \%\end{array}$ & $\begin{array}{c}1 \\
0 \%\end{array}$ & $\begin{array}{c}2003 \\
100 \%\end{array}$ \\
\hline
\end{tabular}

Tab. 7. Distribución de los restos líticos del abrigo de l'Areny por categorías y materias primas. 
más representadas son las lascas $(23,9 \%)$ y sus fragmentos $(22,7 \%)$. Los retocados son un 7,9\% y los núcleos un 1,5\%. El 65,5\% del material está patinado pero sin llegar al grado de alteración de la Mallada, y el 52,1\% presenta evidencias de alteración térmica.

Se han contabilizado 30 núcleos (29 sobre sílex y 1 sobre ágata) de dimensiones reducidas: 15 se ubican en el módulo "Pequeño", 11 en el "Mediano", 2 en el "Muy pequeño" y 1 en el "Grande" y "Muy grande". Estos núcleos están en una fase de explotación plena $(n=18)$ o final $(n=12)$, es decir, reflejan una secuencia de explotación avanzada, con un aprovechamiento máximo de la materia prima. Se han determinado 43 planos de intervención: núcleos unipolares $(\mathrm{n}=18)$, bipolares $(\mathrm{n}=11)$ y 1 con tres planos. El plano más utilizado es el transversal con 28, el horizontal con 9 y el sagital con 6 , lo que favorece la obtención de láminas o productos donde destaca la longitud sobre la anchura.

Estos núcleos evidencian una talla en superficie y en volumen. A partir de su organización volumétrica y la disposición de las extracciones se han definido 4 modelos. El más destacado incluye los núcleos con una explotación longitudinal y jerarquización facial $(n=12)$ (Fig. 5). La talla es en superficie y sigue la misma organización volumétrica expuesta en los núcleos de la Mallada. El plano de intervención más utilizado es el transversal con 11, el sagital con 4 y el horizontal con 1. De estos núcleos hay 8 unipolares, 4 explotados desde el transversal (Fig. 5: 1-3) y 4 desde el sagital (Fig. 5: 4-6), y 3 bipolares opuestos explotados desde los planos transversales (Fig. 5: 7-9). El núcleo restante es bipolar ortogonal con el plano de intervención horizontal y el transversal, perpendiculares entre sí (Fig. 5: 10). Los unipolares y bipolares presentan levantamientos unidireccionales y paralelos en una serie o dos series opuestas respectivamente. Los levantamientos laminares se observan en los núcleos 1, 4, 5 y 8 . En el resto se busca la obtención de lascas más largas que anchas.

El segundo modelo de talla en superficie engloba los núcleos con estructura discoidal y extracciones centrípetas $(n=4)$ (Fig. 6: 1-4): 3 son explotados desde el plano horizontal (Fig. 6: 1, 3 y 4) y 1 desde los dos transversales y el horizontal, aunque la mayoría de las extracciones se realizan desde los transversales (Fig. 6: 2).

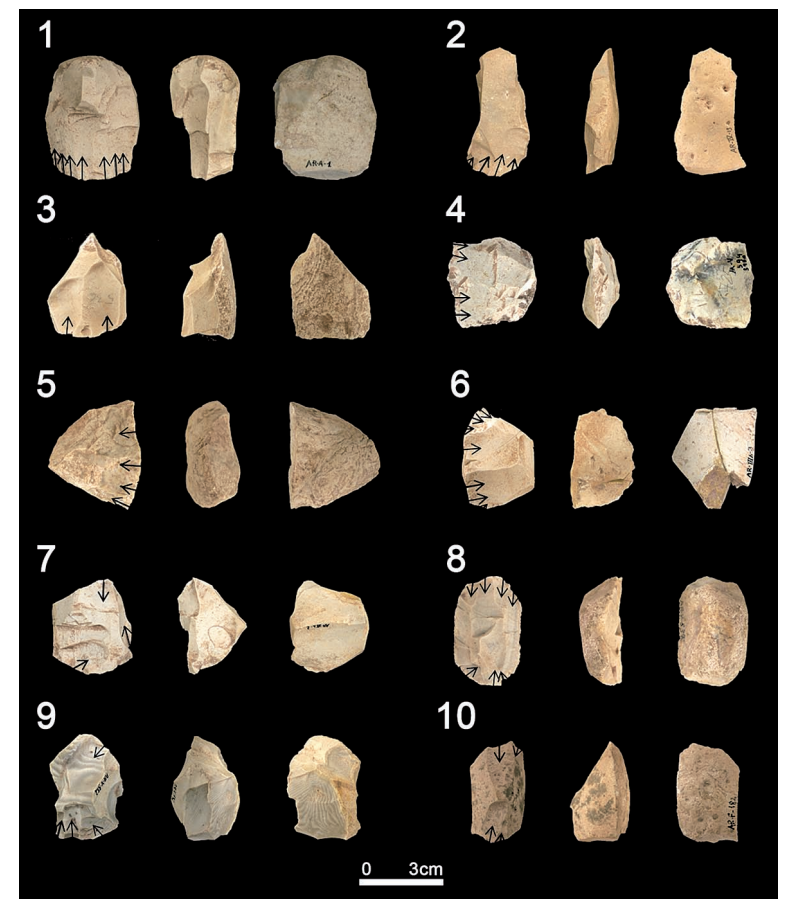

Fig. 5. Núcleos recuperados en l'Areny con explotación longitudinal y jerarquización facial (fotografías Sergio García).

La organización volumétrica sigue el mismo patrón que el modelo anterior. Presentan dos caras opuestas separadas por un plano de intersección pero, a excepción del número 2 , son núcleos bifaciales sin jerarquización facial. Por tanto, parece haber continuidad entre este modelo y el anterior, aunque en este caso los núcleos están destinados a la obtención de lascas sin ningún interés por maximizar la longitud. También se observa esta continuidad con los núcleos bipolares opuestos que se comentarán a continuación.

El tercer modelo abarca los núcleos explotados de forma longitudinal y en volumen $(n=8)$, los cuales pueden ser unipolares $(n=4)$ o bipolares opuestos $(n=4)$. Los unipolares son explotados desde el plano transversal y reflejan una talla laminar (Fig. 6: 5-8). El perímetro de todos los planos de intervención está muy explotado y las extracciones son abruptas o semiabruptas, lo que confiere a los núcleos morfologías piramidales. Además, el número 6 presenta pequeños levantamientos distales para conservar la morfología adecuada y continuar obteniendo láminas. Estos núcleos unipolares mantienen una continuidad

Trab. Prehist., 72, N. ${ }^{\circ}$ 1, enero-junio 2015, pp. 64-83, ISSN: 0082-5638

doi: $10.3989 /$ tp. 2015.12144 


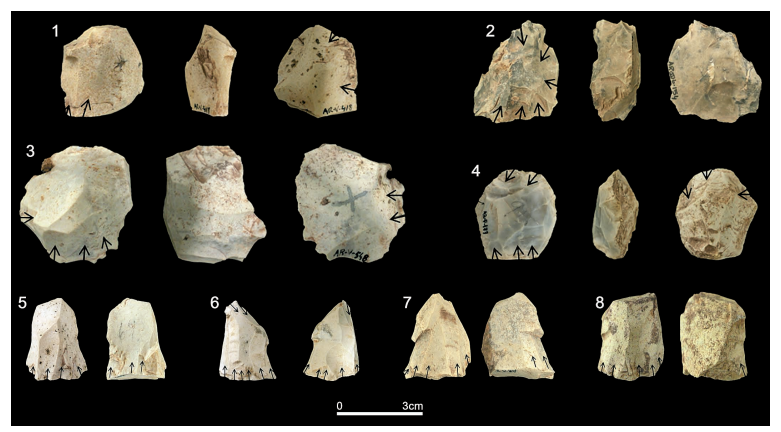

Fig. 6. Núcleos recuperados en l'Areny: 1-4. núcleos centrípetos con estructura discoidal; 5-8. núcleos con explotación longitudinal y en volumen (fotografías Sergio García).

con los núcleos con jerarquización facial ya que podrían resultar de continuar la talla en estos núcleos jerarquizados. Todos los bipolares opuestos (Fig. 7: 1-4) explotan los dos planos transversales. En el número 1 hay pequeños levantamientos para crear una cresta o acondicionar la superficie de talla para facilitar posteriores extracciones. En estos núcleos se evidencia una talla laminar. Los últimos levantamientos han sido fallidos ya que hay muchos reflejados que han provocado su abandono. Estos núcleos mantienen una relación de continuidad con los unipolares explotados en volumen, como se ve sobre todo en los núcleos 2 y 4.

El cuarto modelo incluye los núcleos expeditivos $(n=6)$ (Fig. 7: 5-8). Son explotados de forma oportunista, sin preparación del volumen. Todos son unipolares: en 3 se utiliza el transversal, en 2 el sagital y en 1 el horizontal. Las extracciones son pocas y sin intentar obtener productos laminares o con tendencia laminar. Las series de levantamientos son cortas salvo en el número 6 con extracciones en gran parte de su perímetro.

Estos núcleos evidencian que la talla laminar ocupa un lugar destacado en los procesos de producción y se ha llevado a cabo sobre diferentes estructuras volumétricas. Reafirman la importancia de esta talla cuatro láminas de cresta y varias lascas con sección triangular pronunciada. Los núcleos discoidales y los explotados en volumen tienen un papel más destacado que en la Mallada.

Se han analizado 478 lascas: 468 sobre sílex, 8 sobre ágata y 2 sobre cuarcita. La media de las

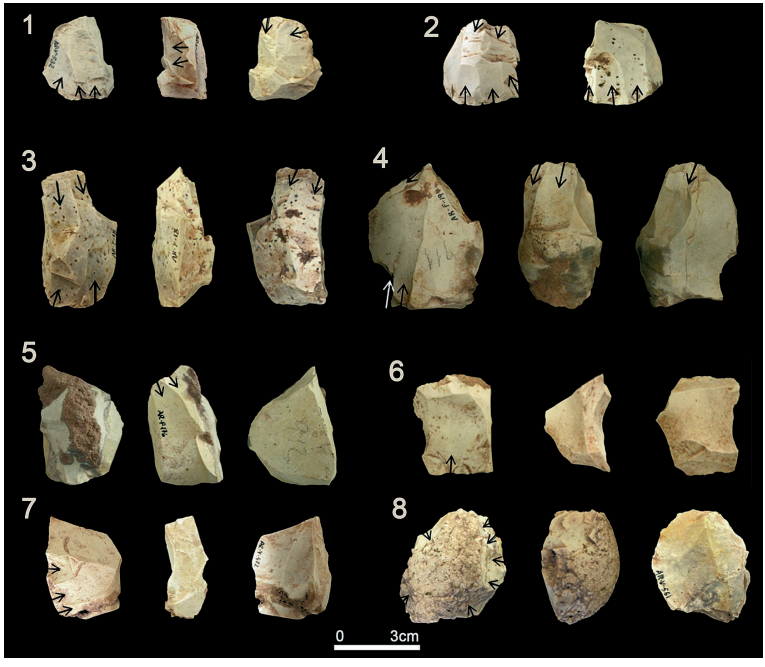

Fig. 7. Núcleos recuperados en l'Areny: 1-4. núcleos bipolares opuestos con explotación en volumen; 5-8. núcleos expeditivos (fotografías Sergio García).

tres dimensiones indica que las lascas sobre ágata son ligeramente más largas, más estrechas y más delgadas que las producidas sobre sílex. Las de cuarcita tienen dimensiones muy superiores. En la clasificación de las lascas en módulos volumétricos, de alargamiento y de carenado no ha intervenido la materia prima por la poca representatividad del ágata y de la cuarcita. Los módulos "Pequeño" y "Muy pequeño" suponen un $85,1 \%$ y los dos que implican las mayores dimensiones un $6 \%$ (Tab. 8). Los productos laminares son un $22,8 \%$ (Tab. 9), pero el porcentaje aumentaría si se incluyeran los productos fracturados y los retocados. Según el índice de carenado se prefieren las lascas espesas ya que las delgadas suponen sólo un 29,5\% (Tab. 10).

Las características morfotécnicas de las lascas indican que el talón es no cortical, unifacetado.

\begin{tabular}{|c|c|c|c|c|c|c|}
\hline & $\begin{array}{c}\text { Muy } \\
\text { pequeño }\end{array}$ & Pequeño & Mediano & Grande & $\begin{array}{c}\text { Muy } \\
\text { grande }\end{array}$ & Total \\
\hline Lascas & $\begin{array}{c}254 \\
53,1 \%\end{array}$ & $\begin{array}{c}153 \\
32 \%\end{array}$ & $\begin{array}{c}42 \\
8,8 \%\end{array}$ & $\begin{array}{c}14 \\
2,9 \%\end{array}$ & $\begin{array}{c}15 \\
3,1 \%\end{array}$ & $\begin{array}{c}478 \\
100 \%\end{array}$ \\
\hline $\begin{array}{c}\text { Retocados } \\
\text { sobre } \\
\text { lasca }\end{array}$ & $\begin{array}{c}18 \\
29,5 \%\end{array}$ & $\begin{array}{c}27 \\
44,3 \%\end{array}$ & $\begin{array}{c}12 \\
19,7 \%\end{array}$ & $\begin{array}{c}2 \\
3,3 \%\end{array}$ & $\begin{array}{c}2 \\
3,3 \%\end{array}$ & $\begin{array}{c}61 \\
100 \%\end{array}$ \\
\hline
\end{tabular}

Tab. 8. Distribución de las lascas y los retocados sobre lasca de l'Areny por módulos volumétricos. 


\begin{tabular}{|c|c|c|c|c|c|c|c|c|c|c|}
\hline & $\mathbf{L 1}$ & $\mathbf{L 2}$ & $\mathbf{L 3}$ & $\mathbf{L 4}$ & $\mathbf{L 5}$ & $\mathbf{L 6}$ & $\mathbf{L 7}$ & $\mathbf{L 8}$ & $\mathbf{L 9}$ & Total \\
\hline Lascas & 1 & 106 & 166 & 96 & 60 & 22 & 13 & 7 & 7 & $\mathbf{4 7 8}$ \\
&, $2 \%$ & $22,2 \%$ & $34,7 \%$ & $20,1 \%$ & $12,6 \%$ & $4,6 \%$ & $2,7 \%$ & $1,5 \%$ & $1,5 \%$ & $\mathbf{1 0 0 \%}$ \\
\hline $\begin{array}{c}\text { Retocados } \\
\text { sobre lasca }\end{array}$ & & 14 & 25 & 13 & 4 & 3 & 2 & & & $\mathbf{6 1}$ \\
\hline
\end{tabular}

Tab. 9. Distribución de las lascas y los retocados sobre lasca de l'Areny por módulos de alargamiento.

\begin{tabular}{|c|c|c|c|c|c|c|c|c|c|c|}
\hline & C1 & C2 & C3 & C4 & C5 & C6 & C7 & C8 & C9 & Total \\
\hline Lascas & 2 & 71 & 145 & 119 & 86 & 34 & 8 & 6 & 7 & $\mathbf{4 7 8}$ \\
&, $4 \%$ & $14,9 \%$ & $30,3 \%$ & $24,9 \%$ & $18 \%$ & $7,1 \%$ & $1,7 \%$ & $1,3 \%$ & $1,4 \%$ & $\mathbf{1 0 0 \%}$ \\
\hline $\begin{array}{c}\text { Retocados } \\
\text { sobre lasca }\end{array}$ & $1,6 \%$ & 6 & 28 & 18 & 8 & & & & & $\mathbf{6 1}$ \\
\hline
\end{tabular}

Tab. 10. Distribución de las lascas y los retocados sobre lasca de l'Areny por módulos de carenado.

Como superficie domina la plataforma sobre la lineal $(62,6 \%$ y $25,7 \%)$. Hay más bulbos difusos $(58,2 \%)$ que marcados $(41,8 \%)$. El $67,4 \%$ de la cara dorsal de las lascas no presenta córtex, en el $7,7 \%$ domina la parte cortical y en el $4,6 \%$ es totalmente cortical. Por tanto, la materia prima es introducida al yacimiento ligeramente desbastada.

Los artefactos retocados están configurados sobre sílex salvo 4 sobre ágata. Hay 61 retocados sobre lasca, 13 sobre lasca fracturada y 85 sobre fragmento de lasca. Para el estudio tipométrico no se han separado los objetos por materias primas. La media de las tres dimensiones muestra valores superiores a los que reflejan las lascas, lo que sugiere que el tamaño era un criterio importante a la hora de seleccionar los soportes a configurar. Por módulos volumétricos los más pequeños representan el 73,8\% y, al contrario de lo que sucede con las lascas, domina el "Pequeño" (Tab. 8). En los módulos "Mediano", "Grande" y "Muy Grande" el porcentaje es mayor en los retocados que en las lascas. Si comparamos esta distribución con la de las lascas las diferencias son significativas $\left(\mathrm{x}^{2}=14,84 ; \mathrm{gl}=4 ; \mathrm{P}<0,05\right)$, es decir, se tiende a seleccionar productos más grandes para configurar los retocados. El índice de alargamiento sigue la misma pauta que en las lascas (Tab. 9). El 14,8\% de estos artefactos se incluye en los módulos laminares, lo que supone un descenso con respecto a las lascas. No obstante, la diferencia no es estadísticamente significativa $\left(\mathrm{x}^{2}=4,28 ; \mathrm{gl}=9 ; \mathrm{P}>0,05\right)$. Hay que tener presente que la mayoría de dorsos no aparecen por estar fracturados, por lo que el componente laminar sería mayor si se hubiesen recuperado enteros. El índice de carenado muestra que el 13,1\% son configurados sobre soportes delgados (Tab. 10), y si se compara con las lascas, hay más elementos espesos entre los retocados. Por tanto, el espesor parece otro criterio para seleccionar soportes, pero no hay que olvidar que la mayoría de dorsos no están representados.
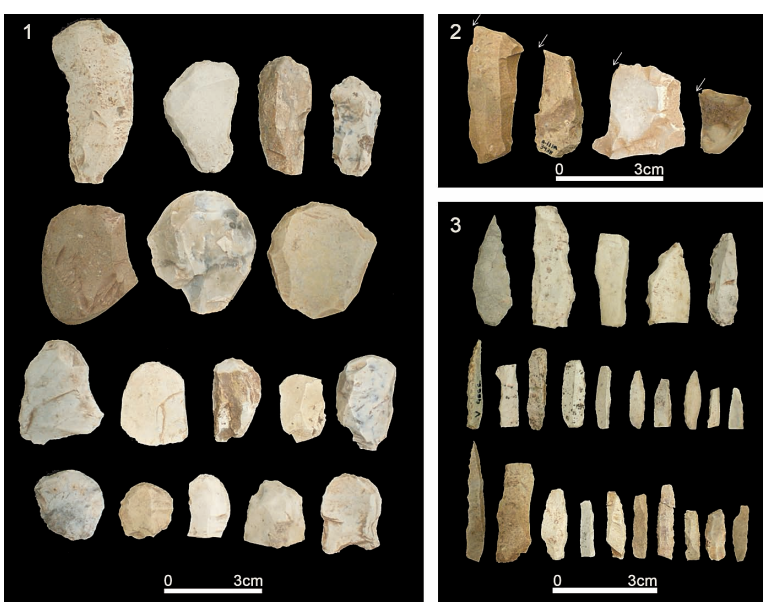

Fig. 8. Artefactos retocados recuperados en l'Areny: 1. raspadores; 2 . buriles; 3 . elementos de dorso (fotografías Sergio García). 
Hay un total de 163 tipos primarios (4 dobles). Predomina el modo de retoque simple (50,31\%), seguido del abrupto $(37,42 \%)$. El buril aparece en un $2,45 \%$. El retoque semiabrupto se da en un 9,82\%. En los grupos tipológicos (Tab. 5) (Fig. 8), predominan los raspadores $(38,7 \%)$, los dorsos $(28,1 \%)$ y los denticulados $(14,1 \%)$. Los porcentajes del resto de tipos son pequeños, caso de los buriles. En los tipos primarios (Tab. 6) de los raspadores domina el raspador frontal simple (G11). Entre los denticulados no destaca ningún tipo aunque la muesca (D21) y la raedera denticulada (D23) son los más representados. La lámina de dorso profundo (LD21) y la punta de dorso total (PD23) son las más frecuentes.

La alteración térmica se da en el $24,5 \%$ de los retocados sin haber podido establecer con seguridad que los retoques se hicieran tras dicha alteración y, por tanto, determinar la práctica del reciclaje.

\section{DISCUSIÓN Y CONCLUSIONES}

El estudio de estos conjuntos pone de manifiesto que comparten la mayor parte de las características tecnológicas y tipológicas y que las diferencias son mínimas. Los núcleos muestran un grado de explotación similar, utilizando planos de intervención según un mismo patrón con predominio del plano transversal. Los núcleos más representados son los de jerarquización facial, los explotados en volumen y los de estructura discoidal, cuya presencia es mucho más destacada en l'Areny. En ambos yacimientos la talla laminar ocupa un lugar destacado en los procesos de producción con más peso en la Mallada y sigue tres procedimientos sin que se pueda determinar el predominio de ninguno. Se puede configurar una arista guía que permita la primera extracción (lámina de cresta), utilizar una arista natural formada por la intersección de dos planos o explotar lascas espesas.

Las lascas tienen características tipométricas y morfotécnicas muy similares. La diferencia más significativa es que son más estrechas y el índice laminar es mayor en l'Areny. En ambos conjuntos para la configuración de los retocados se seleccionan soportes mayores que las lascas. Además, y dejando a un lado los dorsos, se buscan soportes espesos pero no laminares. Predomina el modo de retoque simple, sobre todo en l'Areny. La gran diferencia entre ambos conjuntos está en que los buriles son significativos en la Mallada y escasos en l'Areny. Los grupos tipológicos predominantes son el de los raspadores y los dorsos, ambos más representados en l'Areny. El tercero con mayor presencia es el buril en la Mallada y los denticulados en l'Areny.

Ambos conjuntos difieren en tecnología y tipología. Usan los mismos procesos de producción y no se evidencia una simplificación de estos procesos. La diferencia reside en que la talla laminar domina en la Mallada y las producciones de láminas y lascas comparten protagonismo en l'Areny. La diferencia tipológica reside en la importante presencia de buriles en la Mallada que favoreció su inclusión en el MS y su escasez en l'Areny que la incluyó en el EM.

Varios autores defienden que los procesos de producción laminares se simplifican en el EM con respecto al Magdaleniense (Domènech 1998; Soler et al. 2009). Esto es difícil de contrastar en la vertiente mediterránea peninsular ya que son pocos los yacimientos con una secuencia estratigráfica suficiente. Sin embargo, una cierta simplificación tecnológica se puede entrever en la cueva del Parco (Alòs de Balaguer, Lleida) y en la cueva Matutano (Vilafamés, Castellón). En el Parco hay niveles atribuidos a ambos periodos cronoculturales (Fullola et al. 2006; Mangado et al. 2007; Mangado et al. 2009; Petit et al. 2009). En el nivel II, atribuido al Magdaleniense superior final (MSF), domina la talla laminar sobre la talla para obtener lascas. Se lleva a cabo mediante tres procesos: configurar una arista guía (el más utilizado y el más complejo), aprovechar una arista natural formada por dos planos o explotar lascas espesas. Sobre este nivel se sitúan los niveles Ib e Ic incluidos en el EM. Como en el nivel II, la talla laminar es la preponderante, pero aquí se prefiere no configurar una arista guía. En Matutano (Domènech 1998), y sin entrar en detalles respecto a los niveles definidos en los diversos sondeos, podemos hablar de dos grupos: los niveles inferiores atribuidos al MS y los superiores incluidos en el Epimagdaleniense. En los niveles inferiores, en la talla laminar se configuran aristas guía y hay un continuo acondicionamiento y regularización de los núcleos. En cambio, en los superiores esta talla ofrece 
esquemas más simples ya que se aprovecha la intersección de dos planos y, en algún caso, se configura una arista guía. Por tanto, en ambos yacimientos los procesos con mayor dificultad técnica pasan a un segundo plano en favor de los más simples.

Dada la mayor antigüedad otorgada a la Mallada con respecto a l'Areny, cabría esperar que esta simplificación tecnológica pudiera determinarse. Sin embargo, tras analizar los núcleos y productos obtenidos y definir los procesos de producción, llegamos a la conclusión que dicha simplificación no se produce. Hay una continuidad tecnológica entre ambos yacimientos y no se pueden establecer diferencias en la complejidad de estos procesos. También se observa esta continuidad tecnológica en los conjuntos $\mathrm{B}$ y $\mathrm{C}$ del abrigo de la Cativera (El Catllar, Tarragona), los cuales se incluyen dentro de la secuencia MSF/ EM (Fontanals et al. 2009) (3). Otros casos para evaluar si se produce esta continuidad o hay una simplificación de las estrategias de producción podrían ser los conjuntos A y B del Molí del Salt (Vaquero 2004; García 2007; García et al. 2013), pero faltan suficientes datos para el conjunto B. En esta misma disyuntiva se sitúan los niveles E, EJ y $\mathrm{K}$ de la Balma Guilanyà (Navès, Lleida), incluidos en el Aziliense (Casanova et al. 2008; Martínez-Moreno y Mora 2009). Los niveles EJ y $\mathrm{K}$ cuentan con poco material y no han permitido establecer si hay continuidad tecnológica con el nivel E. Otros conjuntos que permitirían ver esta posible continuidad son los niveles II y IV dels Colls (Margalef de Montsant, Tarragona) (Fullola et al. 1993; Fullola et al. 1995; Fullola et al. 2012) y los niveles I, II y III del Tossal de la Roca (Vall d'Alcalà, Alicante) (Cacho et al. 2001), pero en las diversas publicaciones no se hace referencia a las estrategias de talla.

Tras el análisis tecnológico de la Mallada y l'Areny, en la bibliografía publicada se han buscado paralelismos con otros yacimientos del sur de Cataluña y algunos situados más al Norte con dataciones radiométricas incluidas en el PSF (Tab. 11). Se han dejado de lado conjuntos arqueológicos datados pero con escaso material como el ni-

(3) Morales, J. I. 2010: La Cativera (Tarragona): la tecnología lítica de los últimos cazadores-recolectores en el Noreste de la Península Ibérica. Tesis de Máster inédita. Universidad Rovira i Virgili de Tarragona. Tarragona. vel IIB de Picamoixons (Picamoixons, Tarragona) (García et al. 2009), el nivel 21 de la cueva de Can Sadurní (Begues, Barcelona) (Fullola et al. 2011) y los niveles EJ y K de Guilanyà.

El conjunto de la Mallada permite establecer paralelismos con el nivel II del Parco y los niveles II y IV dels Colls. El nivel más próximo a la Mallada es el nivel IV dels Colls ya que domina el retoque simple y los raspadores son los más representados. En los otros dos niveles el dominio del retoque abrupto favorece que los dorsos sean los más representados. En cambio, l'Areny se asemeja sobre todo al conjunto A del Molí del Salt, a los conjuntos B y C de la Cativera, Font Voltada (Montbrió de la Marca, Tarragona) (Mir y Freixas 1993), al nivel II del Hort de la Boquera (Margalef de Montsant, Tarragona) (Mangado et al. 2010; Fullola et al. 2012), a la parte inferior del nivel 1 de la Balma del Gai (Moià, Barcelona) (García-Argüelles et al. 2009) y al nivel IIIa de la cueva de la Guineu (Font-Rubí, Barcelona) (Equipo Guineu 1995). Hay otros conjuntos con las mismas características que l'Areny que difieren solo en la mayor presencia del retoque abrupto, el cual se equipara al simple e incluso lo supera: Clot de l'Hospital (Roquetes, Tarragona) (Genera 1993; Esteve 2000), los niveles 1 y 2 de la cueva del Vidre (Roquetes, Tarragona) (Bosch 2001; Esteve 2000), el nivel 8/9 del abrigo del Filador (Margalef de Montsant, Tarragona) (GarcíaArgüelles et al. 2005), el nivel $\mathrm{E}$ de Guilanyà $\mathrm{o}$ el conjunto B del Molí del Salt.

Para finalizar, haremos referencia a la supuesta mayor antigüedad de la Mallada con respecto a l'Areny. Hay conjuntos arqueológicos con escasos buriles (conjunto B del Molí del Salt o nivel II del Hort de la Boquera) que muestran dataciones similares y tan antiguas como los yacimientos con una buena presencia de este tipo de retocados. Por ello resulta arriesgado asegurar la mayor antigüedad de la Mallada sin disponer de dataciones radiométricas. En general, los yacimientos incluidos en el MS y EM presentan las mismas características tecnológicas y tipológicas. Las pequeñas diferencias entre ellos formarían parte de la variabilidad propia del PSF y no bastan para definir dos periodos cronoculturales distintos. En consecuencia, pensamos que no es necesario mantener la distinción MS-EM.

En resumen, los conjuntos líticos de la Mallada y l'Areny presentan una continuidad tecno-

Trab. Prehist., 72, N. ${ }^{\circ}$ 1, enero-junio 2015, pp. 64-83, ISSN: 0082-5638

doi: $10.3989 /$ tp.2015.12144 


\begin{tabular}{|c|c|c|c|c|c|c|c|}
\hline Yacimiento & Nivel & $\begin{array}{l}\text { Referencia de } \\
\text { laboratorio }\end{array}$ & Material & Años BP & $\begin{array}{c}\text { Años Cal BP } \\
(2 \sigma)\end{array}$ & $\begin{array}{c}\text { Periodo } \\
\text { cronocultural }\end{array}$ & Bibliografía \\
\hline Molí del Salt & Asup & Beta-179599 & Carbón & $10840 \pm 50$ & $12890-12690$ & MSF & Vaquero 2004 \\
\hline Molí del Salt & Asup & Beta-179598 & Carbón & $10990 \pm 50$ & $13050-12730$ & MSF & Vaquero 2004 \\
\hline Molí del Salt & Asup & Beta-221912 & Carbón & $11060 \pm 70$ & $13130-12770$ & MSF & Vaquero et al. 2012 \\
\hline Molí del Salt & Asup & Beta-221913 & Carbón & $10850 \pm 70$ & $12950-12670$ & MSF & Vaquero et al. 2012 \\
\hline Molí del Salt & Asup & Beta-235268 & Carbón & $10920 \pm 60$ & $12990-12710$ & MSF & Vaquero et al. 2012 \\
\hline Molí del Salt & $\mathrm{A}$ & Beta-235267 & Carbón & $11000 \pm 60$ & $13080-12720$ & MSF & Vaquero et al. 2012 \\
\hline Molí del Salt & A & Beta-277000 & Carbón & $11230 \pm 50$ & $13270-13030$ & MSF & Vaquero et al. 2012 \\
\hline Molí del Salt & A & Beta-277001 & Carbón & $11440 \pm 60$ & $13500-13180$ & MSF & Vaquero et al. 2012 \\
\hline Molí del Salt & $\mathrm{A}$ & Beta-284214 & Carbón & $10940 \pm 50$ & $12990-12710$ & MSF & Vaquero et al. 2012 \\
\hline Molí del Salt & $\mathrm{A}$ & Beta-284212 & Carbón & $11770 \pm 50$ & $13790-13550$ & MSF & Vaquero et al. 2012 \\
\hline Molí del Salt & A & Beta-284213 & Carbón & $11800 \pm 50$ & $13800-13560$ & MSF & Vaquero et al. 2012 \\
\hline Molí del Salt & B1 & GifA-101037 & Carbón & $11940 \pm 100$ & $14070-13590$ & MS & Vaquero 2004 \\
\hline Molí del Salt & $\mathrm{B} 2$ & GifA-101038 & Carbón & $12510 \pm 100$ & $15300-14540$ & MS & Vaquero 2004 \\
\hline Parco & $\mathrm{Ib}$ & OxA-8656 & Carbón & $11430 \pm 60$ & $13470-13190$ & EM & $\begin{array}{l}\text { García-Argüelles y } \\
\text { Fullola } 2006\end{array}$ \\
\hline Parco & Ic & OxA-8657 & Carbón & $11270 \pm 90$ & $13350-12990$ & EM & $\begin{array}{l}\text { García-Argüelles y } \\
\text { Fullola } 2006\end{array}$ \\
\hline Parco & II & OxA-10796 & Carbón & $12605 \pm 60$ & $15320-14840$ & M epigonal & Mangado et al. 2007 \\
\hline Parco & II & OxA-10797 & Carbón & $12460 \pm 60$ & $15080-14600$ & MSF & Fullola et al. 2006 \\
\hline Parco & II & OxA-10835 & Carbón & $12560 \pm 130$ & $15450-14530$ & MSF & Mangado et al. 2007 \\
\hline Parco & II & OxA-10798 & Carbón & $13175 \pm 60$ & $16600-15480$ & MSF & Fullola et al. 2006 \\
\hline Parco & II & OxA-13597 & Carbón & $12995 \pm 50$ & $15690-15450$ & MSF & Mangado et al. 2007 \\
\hline Parco & II & OxA-13596 & Carbón & $13025 \pm 50$ & $15840-15440$ & MSF & Mangado et al. 2007 \\
\hline Parco & II & OxA-17730 & Carbón & $13095 \pm 55$ & $16390-15390$ & MS & Mangado et al. 2010 \\
\hline $\begin{array}{l}\text { Hort de la } \\
\text { Boquera }\end{array}$ & II & OxA-13595 & Carbón & $12250 \pm 60$ & $14810-13890$ & PSF (M) & Fullola 2006 \\
\hline $\begin{array}{l}\text { Hort de la } \\
\text { Boquera }\end{array}$ & II & OxA-23646 & Carbón & $11850 \pm 45$ & $13850-13570$ & PSF (M) & Fullola et al. 2012 \\
\hline $\begin{array}{l}\text { Hort de la } \\
\text { Boquera }\end{array}$ & II & OxA-23645 & Carbón & $11775 \pm 45$ & $13790-13550$ & PSF (M) & Fullola et al. 2012 \\
\hline La Cativera & $\mathrm{B}$ & AA-23368 & Carbón & $8860 \pm 95$ & $10300-9580$ & EM & Fontanals et al. 2009 \\
\hline La Cativera & $\mathrm{B}$ & Beta.281623 & Carbón & $8230 \pm 40$ & $9340-9060$ & EM & Fontanals et al. 2009 \\
\hline La Cativera & $\mathrm{C} 1$ & AA-23369 & Carbón & $10370 \pm 100$ & $12700-11860$ & EM & Fontanals et al. 2009 \\
\hline La Cativera & $\mathrm{C} 2$ & AA-23370 & Carbón & $10660 \pm 120$ & $12880-12280$ & EM & Fontanals et al. 2009 \\
\hline La Cativera & $\mathrm{C} 3$ & AA-23371 & Carbón & $11230 \pm 100$ & $13330-12930$ & EM & Fontanals et al. 2009 \\
\hline La Cativera & $\mathrm{C} 3 \mathrm{~b}$ & AA-23372 & Carbón & $11135 \pm 80$ & $13260-12820$ & EM & Fontanals et al. 2009 \\
\hline Filador & $8-9$ & OxA-8660 & Carbón & $11000 \pm 55$ & $13080-12720$ & EM & $\begin{array}{c}\text { García-Argüelles et } \\
\text { al. } 2005\end{array}$ \\
\hline
\end{tabular}

Tab. 11 (1). Dataciones radiométricas del Paleolítico superior final en Cataluña (calibradas utilizando la curva de calibración CalPal2007-HULU del programa de calibración CalPal). Los espacios en blanco se deben a la falta de información publicada. MSF Magdaleniense superior final; MS Magnaleniense superior; PSF Paleolítico superior final; (M) Magdalaniense; EM Epipaleolítico microlaminar. 


\begin{tabular}{|c|c|c|c|c|c|c|c|}
\hline Yacimiento & Nivel & $\begin{array}{l}\text { Referencia de } \\
\text { laboratorio }\end{array}$ & Material & Años BP & $\begin{array}{c}\text { Años Cal BP } \\
\qquad(2 \sigma)\end{array}$ & $\begin{array}{c}\text { Periodo } \\
\text { cronocultural }\end{array}$ & Bibliografía \\
\hline Filador & $8-9$ & OxA-8659 & Carbón & $10880 \pm 60$ & $12940-12700$ & EM & $\begin{array}{c}\text { García-Argüelles et } \\
\text { al. } 2005\end{array}$ \\
\hline Els Colls & II & OX TL-270 & Sílex & $13000 \pm 1000$ & $18270-12790$ & EM & Fullola et al. 1993 \\
\hline Els Colls & II & AA-8645 & Carbón & $10950 \pm 120$ & $13110-12670$ & EM & Fullola, et al. 1995 \\
\hline Els Colls & II & AA-8646 & Carbón & $10050 \pm 85$ & $11890-11220$ & EM & Fullola 1996 \\
\hline Els Colls & IV & GifA-95544 & & $12150 \pm 120$ & $14790-13710$ & PSF (M) & Fullola et al. 2012 \\
\hline Els Colls & IV & GifA-95571 & & $12490 \pm 120$ & $15350-14350$ & PSF (M) & Fullola et al. 2012 \\
\hline Picamoixons & IIB & AA-5810 & Carbón & $11055 \pm 90$ & $13150-12750$ & EM & García et al. 2009 \\
\hline $\begin{array}{c}\text { Clot de } \\
\text { 1'Hospital }\end{array}$ & & OxA-16421 & Hueso & $11115 \pm 50$ & $13130-12890$ & EM & Morales et al. 2012 \\
\hline $\begin{array}{c}\text { Clot de } \\
\text { l'Hospital }\end{array}$ & & OxA-16422 & Hueso & $10045 \pm 45$ & $11850-11290$ & EM & Morales et al. 2012 \\
\hline Cova del Vidre & II & Beta-58933 & Carbón & $10740 \pm 130$ & $12930-12490$ & $\mathrm{EM}$ & Bosch 2001 \\
\hline Font Voltada & & UBAR-72 & Carbón & $10920 \pm 240$ & $13290-12450$ & Epigravetiense & Mir y Freixas 1993 \\
\hline La Guineu & IIIa & Gif-8439 & Carbón & $9850 \pm 80$ & $11520-11120$ & EM & Equip Guineu 1995 \\
\hline Balma del Gai & 1 & MC-2140 & & $10050 \pm 160$ & $12240-11080$ & EM & $\begin{array}{c}\text { García-Argüelles et } \\
\text { al. } 2009\end{array}$ \\
\hline Balma del Gai & 1 & GifA-95617 & & $10260 \pm 90$ & $12520-11600$ & EM & $\begin{array}{c}\text { García-Argüelles et } \\
\text { al. } 2009\end{array}$ \\
\hline Balma del Gai & 1 & GifA-95630 & & $12240 \pm 110$ & $14900-13820$ & EM & $\begin{array}{c}\text { García-Argüelles et } \\
\text { al. } 2009\end{array}$ \\
\hline $\begin{array}{c}\text { Balma } \\
\text { Guilanyà }\end{array}$ & $\mathrm{K}$ & Beta-247708 & Carbón & $12310 \pm 40$ & $14850-14090$ & Aziliense & $\begin{array}{c}\text { Martínez-Moreno y } \\
\text { Mora } 2009\end{array}$ \\
\hline $\begin{array}{c}\text { Balma } \\
\text { Guilanyà }\end{array}$ & EJ & Beta-185066 & Carbón & $12180 \pm 50$ & $14650-13850$ & Aziliense & Casanova et al. 2008 \\
\hline $\begin{array}{c}\text { Balma } \\
\text { Guilanyà }\end{array}$ & $\mathrm{E}$ & Beta-247706 & Carbón & $11110 \pm 40$ & $13110-12910$ & Aziliense & $\begin{array}{c}\text { Martínez-Moreno y } \\
\text { Mora } 2009\end{array}$ \\
\hline $\begin{array}{c}\text { Balma } \\
\text { Guilanyà }\end{array}$ & $\mathrm{E}$ & Beta-210729 & Corylus & $10940 \pm 50$ & $12990-12710$ & Aziliense & $\begin{array}{c}\text { Martínez-Moreno y } \\
\text { Mora } 2009\end{array}$ \\
\hline $\begin{array}{c}\text { Balma } \\
\text { Guilanyà }\end{array}$ & $\mathrm{E}$ & Ua-34298 & $\begin{array}{c}\text { Hueso } \\
\text { humano }\end{array}$ & $10195 \pm 255$ & $12830-10990$ & Aziliense & $\begin{array}{c}\text { Martínez-Moreno y } \\
\text { Mora } 2009\end{array}$ \\
\hline $\begin{array}{c}\text { Balma } \\
\text { Guilanyà }\end{array}$ & $\mathrm{E}$ & Ua-34297 & $\begin{array}{c}\text { Diente } \\
\text { humano }\end{array}$ & $11095 \pm 195$ & $13380-12660$ & Aziliense & $\begin{array}{c}\text { Martínez-Moreno y } \\
\text { Mora } 2009\end{array}$ \\
\hline Can Sadurní & 21 & Beta-179899 & & $10540 \pm 60$ & $12770-12290$ & EM & Fullola et al. 2011 \\
\hline
\end{tabular}

Tab. 11 (2). Dataciones radiométricas del Paleolítico superior final en Cataluña (calibradas utilizando la curva de calibración CalPal2007-HULU del programa de calibración CalPal). Los espacios en blanco se deben a la falta de información publicada. PSF Paleolítico superior final; (M) Magdalaniense; EM Epipaleolítico microlaminar.

lógica con los mismos sistemas de producción. Las divergencias consisten en el mayor peso de la talla laminar en la Mallada, la gran presencia de buriles en la Mallada y su escasez en l'Areny. A partir de la periodización clásica de Fortea, esta diferencia tipológica ha fundamentado la asig- nación del conjunto arqueológico de la Mallada al MS y el de l'Areny al EM. Pensamos que la distinción entre ambos periodos cronoculturales es discutible ya que comparten gran parte de sus características y las diferencias son mínimas. Según la adscripción tradicional el conjunto de la 
Mallada sería más antiguo que el de l'Areny. En principio, ello es aceptable ya que los conjuntos arqueológicos con una buena representación de buriles suelen tener dataciones más tardías que los que tienen pocos. Pero hay excepciones, conjuntos con escasos buriles y dataciones tan antiguas como los conjuntos con buena presencia de estos retocados. Por ello la supuesta mayor antigüedad de la Mallada sobre l'Areny habría que ponerla en entredicho hasta que se puedan obtener dataciones fiables, lo que por ahora no ha sido posible.

\section{AGRADECIMIENTOS}

Al personal del Museo Arqueológico Salvador Vilaseca de Reus, y en especial a Jaume Massó, que nos ha facilitado la revisión de los materiales arqueológicos depositados en el museo y toda la documentación escrita referente a los dos yacimientos estudiados.

\section{BIBLIOGRAFÍA}

Aura, J. E. 1995: El Magdaleniense mediterráneo: La Cova del Parpalló (Gandía, Valencia). Trabajos varios del Servicio de Investigación Prehistórica 91, Diputación Provincial de Valencia. Valencia.

Aura, J. E. y Pérez, M. 1992: “Tardiglaciar y Postglaciar en la región mediterránea de la Península Ibérica (13500-8500 BP): transformaciones industriales y económicas". Saguntum 25: 25-47.

Aura, J. E. y Pérez, M. 1995: "El Holoceno inicial en el Mediterráneo español (11000-7000 BP). Características culturales y económicas". En V. Villaverde (ed.): Los últimos cazadores. Transformaciones culturales y económicas durante el Tardiglaciar y el inicio del Holoceno en el ámbito mediterráneo: 119-146. Instituto de Cultura Juan Gil-Albert y Diputación Provincial de Alicante. Alicante.

Bosch, J. 2001: "Les ocupacions prehistòriques de caçadors-recol-lectors a la Cova del Vidre (Roquetes): Assentament i clima". Recerca 5: 9-20.

Cacho, C.; Jordá, J.; Torre, I. de la Yravedra, J. 2001: "El Tossal de la Roca (Alicante). Nuevosdatos sobre el Magdaleniense mediterráneo de la Península Ibérica". Trabajos de Prehistoria 58 (1): 71-93.

Carbonell, E.; Rodríguez, X. P.; Sala, R. y Vaquero, M. 1992: "New elements of the logical analytic system". Cahier Noir 6: 5-61.
Casabó, J. A. 2004: Paleolítico superior final y Epipaleolítico en la Comunidad Valenciana. Serie Mayor 3, Museo Arqueológico de Alicante. Alicante.

Casanova, J.; Martínez-Moreno, J. y Mora, R. 2008: "Traçant l'ocupació dels Pirineus: la Balma Guilanyà $\mathrm{i}$ els caçadors recol-lectors del Tardiglacial i l'Holocè antic al Prepirineu Oriental'. Tribuna d'Arqueologia 2006: 59-83.

Domènech, E. M. 1998: "Los sistemas de producción lítica del Paleolítico superior final y Epipaleolítico en la vertiente mediterránea occidental. Tres ejemplos claves: la Grotte Gazel (Salleles-Cabardès, Aude), Cova Matutano (Vilafamés, Castellón) y Abric del Filador (Margalef del Montsant, Tarragona)". Pyrenae 29: 9-45.

Equip Guineu 1995: "Elaboració d'una cronostratigrafia per a la Prehistòria del Penedès". Tribuna d'Arqueologia 1993-1994: 7-24.

Esteve, F. 2000: Recerques arqueològiques a la Ribera Baixa de l'Ebre (1). Prehistòria. Ayuntamiento de Amposta. Amposta.

Font, B.; López-Polín, L. y Ollé, A. 2010: "Description and characterization of the natural alteration of chert artifacts from Atapuerca (Burgos, Spain), Cansaladeta (Tarragona, Spain) and Orgnac 3 (Ardèche, France)". Museologia Scientifica e Naturalistica 6: 103-110.

Fontanals, M.; Ollé, A. y Vergès J. M. 2009: "Les ocupacions del Tardiglacial a l'Abric de La Cativera (El Catllar, Tarragonès)". En Institut d'Estudis Ceretans (ed.): XIV Col-loqui Internacional d'Arqueologia de Puigcerdà. Els Pirineus i les àrees circumdants durant el Tardiglacial. Mutacions i filiacions tecnoculturals, evolució paleoambiental (16000-10000 BP). Homenatge al Professor Georges Laplace (Puigcerdà 2006): 537-547. Puigcerdà.

Fortea, J. 1973: Los complejos microlaminares y geométricos del Epipaleolítico mediterráneo español. Memorias del Seminario de Prehistoria y Arqueología de la Universidad de Salamanca 4. Salamanca.

Fortea, J.; Fullola, J. M.; Villaverde, V.; Davidson, I.; Dupré, M. y Fumanal, M. P. 1983: "Schéma paléoclimatique, faunique et chrono-stratigraphique des industries à bord abattu de la région méditerranéenne espagnole". Rivista di Scienze Preistoriche 38 (1-2): 21-67.

Fullola, J. M. 1996: "Le Paléolithique supérieur dans le nord'est ibérique: la Catalogne". En M. Otte (ed.): Le Paléolithique supérieur européen. Bilan quinquennal 1991-1996 U.I.S.P.P. Commission VIII (Liège 1996). ERAUL 76. Lieja: 345-352.

Fullola, J. M. 2006: "La recherche sur le Paléolithique supérieur dans le NE ibérique: la Catalogne (2001-2005)". En P. Noiret (ed.): Le Paléolithique Supérieur européen. Bilan quinquennal 20012006 U.I.S.P.P. Commission VIII (Lisbonne 2006). ERAUL 115. Lieja: 1-5. 
Fullola, J. M y García-Argüelles, P. 1987: "El Paleolític Superior del sud de Catalunya". Cypsela VI: 237-241.

Fullola, J. M.; Bartrolí, R.; Bergadà, M. M.; Doce, R.; García-Argüelles, P.; Nadal, J.; Rodón, T.; Adserias, M. y Cebrià, A. 1993: "Nuevas aportaciones al conocimiento del Paleolítico superior en las comarcas meridionales y occidentales de Catalunya". En M. P. Fumanal y J. Bernabéu (eds.): Estudios sobre Cuaternario. Medios sedimentarios. Cambios ambientales. Hábitat humano. Universidad de Valencia. Valencia: 239-247.

Fullola, J. M.; García-Argüelles, P.; Mangado, X. y Medina, B. 2011: "Paleolític i Epipaleolític al Garraf-Ordal. On érem i on som...". En A. Blasco, M. Edo y M. J. Villalba (eds.): La Cova de Can Sadurní i la Prehistòria de Garraf. Recull de 30 anys d'investigació. Hugony Editore. Milán: 227-243.

Fullola, J. M.; García-Argüelles, P.; Serrat, D. y Bergadà, M. M. 1995: “El Paleolític i l'Epipaleolític al vessant meridional dels Pirineus catalans. Vint anys de recerca a la franja pirinenca sud; interrelacions amb les àrees circumdants". En Institut d'Estudis Ceretans (ed.): X Col-loqui Internacional d'Arqueologia de Puigcerdà. Cultures i medi. De la Prehistòria a l'Edat Mitjana. 20 anys d'arqueologia pirinenca. Homenatge al Professor Jean Guilaine (Puigcerdà 1995): 159-176. Puigcerdà.

Fullola, J. M.; Mangado, X.; Petit, M. A.; Bartrolí, R. 2006: "La cova del Parco (Alòs de Balaguer, La Noguera, Lleida): Darreres intervencions arqueològiques i visió de conjunt". Quadern de treball de l'Associació Arqueològica de Girona 14: 29-41.

Fullola, J. M.; Mangado, X.; Tejero, J. M.; Petit, M. A.; Bergadà, M. M.; Nadal, J.; García-Argüelles, P.; Bartrolí, R. y Mercadal, O. 2012: "The Magdalenian in Catalonia (northeast I Iberia)". Quaternary International XXX: 1-20.

García-Argüelles, P.; Estrada, A.; Nadal, J.; Fullola, J. M. y Mangado, X. 2009: "Les niveaux épipaléolithiques de la Balma del Gai (Moià, Barcelone, Catalogne)". De Méditerranée et d'ailleurs... Mélanges offerts à Jean Guilaine: 299-310. Archives d'Écologie Préhistorique. Toulouse.

García-Argüelles, P. y Fullola, J. M. 1987: “El Paleolítico superior final en las comarcas meridionales y occidentales de Cataluña". Cuadernos de Prehistoria y Arqueología 13: 17-38.

García-Argüelles, P. y Fullola, J. M. 2006: "La Cueva del Parco (Alós de Balaguer, Lleida) y el Abrigo del Filador (Margalef de Montsant, Tarragona): dos secuencias clave para el conocimiento del Epipaleolítico en el nordeste peninsular". En A. Alday (ed.): El Mesolítico de muescas y denticulados en la cuenca del Ebro y el litoral mediterráneo peninsular. Diputación Foral de Álava. Álava: 121-133.

García-Argüelles, P. y Nadal, J. 1996: "La Cova de la Mallada (Perelló): estudio lítico y reconstrucción paleoecológica de un yacimiento del Paleolítico superior final". Pyrenae 27: 9-20.

García-Argüelles, P.; Nadal, J. y Fullola, J. M. 2005: "El abrigo del Filador (Margalef de Montsant, Tarragona) y su contextualización cultural y cronológica en el nordeste peninsular". Trabajos de Prehistoria 62 (1): 65-83.

García, S. 2007: "La industria lítica del nivel Asup del Molí de Salt (Vimbodí, Tarragona) y su contextualización en el Paleolítico Superior final de la vertiente mediterránea de la Península Ibérica". Trabajos de Prehistoria 64 (2): 157-168.

García, S.; Gómez, B.; Soto, M. y Vaquero, M. 2013: "Los sistemas de producción lítica en el Paleolítico superior final: el caso del nivel Asup del Molí del Salt (Vimbodí i Poblet, Tarragona)". Zephyrus LXXII (2): 39-58.

García, S.; Vaquero, M.; Pérez, I.; Menéndez, B.; Peña, L.; Blasco, R.; Mancha, E.; Moreno, D. y Muñoz, L. 2009: "Palimpsestos y cambios culturales en el límite Pleistoceno-Holoceno: el conjunto lítico de Picamoixons (Alt Camp, Tarragona)". Trabajos de Prehistoria 66 (2): 61-76.

Genera, M. 1993: "Un jaciment quaternari del Baix Ebre: el Clot de l'Hospital'. Homenatge a Miquel Tarradell. Curial Edicions Catalanes. Barcelona: 121-129.

Guilbaud, M. 1995: "Introduction sommaire au concept de champ opératoire”. Cahier Noir 7: 121-133.

Laplace, G. 1974: "La typologie analytique et structurale: Base rationnelle d'étude des industries lithiques et osseuses". Banques de données archéologiques. Colloques nationaux du CNRS (Marseille 1972) 932: 91-143. Paris

Mangado, X.; Petit, M. A.; Fullola, J. M. y Bartrolí, R. 2007: "El Paleolític superior final de la Cova del Parco (Alòs de Balaguer, La Noguera)". Revista d'Arqueologia de Ponent 16-17: 45-62.

Mangado, X.; Petit, M. A.; Fullola, J. M.; Bartrolí, R.; Bergadà, M. M.; Esteve, X.; Calvo, M.;

Tejero, J. M. y Estrada, A. 2009: "Els caçadors recol-lectors de la Cova del Parco (Alòs de Balaguer, La Noguera, Lleida): El Magdalenià superior". En Institut d'Estudis Ceretans (ed.): XIV Col·loqui Internacional d'Arqueologia de Puigcerdà. Els Pirineus $i$ les àrees circumdants durant el Tardiglacial. Mutacions i filiacions tecnoculturals, evolució paleoambiental (16000-10000 BP). Homenatge al Professor Georges Laplace (Puigcerdà 2006): 565577. Puigcerdà.

Mangado, X.; Tejero, J. M.; Fullola, J. M.; GarcíaArgüelles, P.; García, M.; Soler, N. y Vaquero,

M. 2010: "Nuevos territorios, nuevos grafismos: una visión del Paleolítico superior en Catalunya a inicios del siglo XXI". En X. Mangado (ed.): El Paleolítico superior peninsular. Novedades del siglo XXI. Universidad de Barcelona. Barcelona: 63-83. 
Martínez-Moreno, J. y Mora, R. 2009: "Balma Guilanyà (Prepirineo de Lleida) y el Aziliense en el noreste de la Península Ibérica". Trabajos de Prehistoria 66 (2): 45-60.

Mir, A. y Freixas, A. 1993: "La Font Voltada, un yacimiento de finales del Paleolítico Superior en Montbrió de la Marca (La Conca de Barberá, Tarragona)". Cypsela X: 13-21.

Morales, J. I.; Burjachs, F.; Allué, E.; Fontanals, M.; Soto, M. Expósito, I.; Gassiot, E.; Pèlachs, A.; PérezObiol, R.; Soriano, J. M.; Vergès, J. M. y Yll, E. 2012: "Paleografía humana durante el Tardiglaciar y Holoceno inicial en el ámbito mediterráneo del NE Ibérico". Cuaternario y Geomorfología 26 (3-4): 11-28.

Olaria, C. 1999: Cova Matutano (Vilafamés, Castellón). Un modelo ocupacional del magdaleniense superior-final en la vertiente mediterránea peninsular. Monografies de Prehistòria i Arqueologia castellonenques 5, Diputación de Castellón. Castellón.

Petit, M. A.; Mangado, X.; Fullola, J. M.; Bartrolí, R.; Bergadà, M. M. y Esteve, X. 2009: "Els caçadorsrecol-lectors de la Cova del Parco (Alòs de Balaguer, La Noguera, Lleida). L'Epipaleolític microlaminar: continuïtat o canvi?". En Institut d'Estudis Ceretans (ed.): XIV Col-loqui Internacional d'Arqueologia de Puigcerdà. Els Pirineus i les àrees circumdants durant el Tardiglacial. Mutacions i filiacions tecnoculturals, evolució paleoambiental (16000-10000 BP). Homenatge al Professor Georges Laplace (Puigcerdà 2006): 579-591. Puigcerdà.

Román, D. 2010: El poblament del final del Plistocè en les comarques del nord del País Valencià a partir de l'estudi tecno-tipològic de la indústria lítica. Tesis Doctoral. Universidad de Valencia. Valencia. http:// hdl.handle.net/10803/39089 (consulta 27-I-2015).

Soler, N.; Fullola, J. M.; Sacchi, D. y Langlais, M. 2009: "El Magdalenià clàssic entre Llenguadoc occidental i Catalunya (14500-11000 BP)". En Institut d'Estudis Ceretans (ed.): XIV Col-loqui Internacional d'Arqueologia de Puigcerdà. Els Pirineus i les àrees circumdants durant el Tardiglacial. Mutacions i filiacions tecnoculturals, evolució paleoambiental (16000-10000 BP). Homenatge al Professor Georges Laplace (Puigcerdà 2006): 317-348. Puigcerdà.

Vaquero, M. (ed.) 2004: Els darrers caçadorsrecol-lectors de la Conca de Barberà: el jaciment del Moli del Salt (Vimbodi). Excavacions 1999-2003. Museu Arxiu de Montblanc i comarca. Montblanc.

Vaquero, M.; Alonso, S. y García, S. 2009: "El final del Magdaleniense y el Mesolítico en Catalunya". En Institut d'Estudis Ceretans (ed.): XIV Col·loqui Internacional d'Arqueologia de Puigcerdà. Els Pirineus $i$ les àrees circumdants durant el Tardiglacial. Mutacions i filiacions tecnoculturals, evolució paleoambiental (16000-10000 BP). Homenatge al Professor Georges Laplace (Puigcerdà 2006): 349373. Puigcerdà.

Vaquero, M.; Alonso, S.; García, S.; García-Hernández, A.; Gómez, B.; Rettig, D. y Soto, M. 2012: "Temporal nature and recycling of Upper Paleolithic artifacts: the burned tools from the Molí del Salt site (Vimbodí i Poblet, northeastern Spain)". Journal of Archaeological Science XXX: 1-12.

Vilaseca, S. 1961: "La estación taller de sílex de L'Areny (Vilanova d'Escornalbou, provincia de Tarragona)". Trabajos del Seminario de Historia Primitiva del Hombre de la Universidad de Madrid y del Instituto Español de Prehistoria del CSIC III. Madrid: 7-57.

Vilaseca, S. y Cantarell, I. 1956: "La Cova de la Mallada, de Cabra-Feixet". Ampurias XVII-XVIII: 141-157.

Villaverde, V. y Martínez, R. 1995: “Características culturales y económicas del final del Paleolítico superior en el Mediterráneo español". En V. Villaverde (ed.): Los últimos cazadores. Transformaciones culturales y económicas durante el Tardiglaciar y el inicio del Holoceno en el ámbito mediterráneo. Instituto de Cultura Juan Gil-Albert y Diputación Provincial de Alicante. Alicante: 79-117. 